\title{
First-year sea ice melt pond fraction estimation from dual-polarisation C-band SAR - Part 1: In situ observations
}

\author{
R. K. Scharien ${ }^{1}$, J. Landy ${ }^{2}$, and D. G. Barber ${ }^{2}$ \\ ${ }^{1}$ Department of Geography, University of Victoria, Victoria, British Columbia, Canada \\ ${ }^{2}$ Centre for Earth Observation Science, Faculty of Environment Earth and Resources, University of Manitoba, \\ Winnipeg, Manitoba, Canada \\ Correspondence to: R. K. Scharien (randy@uvic.ca)
}

Received: 19 December 2013 - Published in The Cryosphere Discuss.: 27 January 2014

Revised: 28 September 2014 - Accepted: 3 October 2014 - Published: 25 November 2014

\begin{abstract}
Understanding the evolution of melt ponds on Arctic sea ice is important for climate model parameterisations, weather forecast models and process studies involving mass, energy and biogeochemical exchanges across the ocean-sea ice-atmosphere interface. A field campaign was conducted in a region of level first-year sea ice (FYI) in the central Canadian Arctic Archipelago (CAA), during the summer of 2012, to examine the potential for estimating melt pond fraction $\left(f_{\mathrm{p}}\right)$ from satellite synthetic aperture radar (SAR). In this study, $5.5 \mathrm{GHz}$ (C-band) dual co- $(\mathrm{HH}+\mathrm{VV}$ - horizontal transmit and horizontal receive + vertical transmit and vertical receive) and cross-polarisation ( $\mathrm{HV}+\mathrm{HH}-$ horizontal transmit and vertical receive + horizontal transmit and horizontal receive) radar scatterometer measurements of meltpond-covered FYI are combined with ice and pond properties to analyse the effects of in situ physical and morphological changes on backscatter parameters. Surface roughness statistics of ice and ponds are characterised and compared to the validity domains of the Bragg and integral equation model (IEM) scattering models. Experimental and model results are used to outline the potential and limitations of the co-polarisation ratio $(\mathrm{VV} / \mathrm{HH})$ for retrieving melt pond information, including $f_{\mathrm{p}}$, at large incidence angles $\left(\geq 35^{\circ}\right)$. Despite high variability in cross-polarisation ratio $(\mathrm{HV} / \mathrm{HH})$ magnitudes, increases at small incidence angles $\left(<30^{\circ}\right)$ are attributed to the formation of ice lids on ponds. Implications of the results for pond information retrievals from satellite C-, L- and P-band SARs are discussed.
\end{abstract}

\section{Introduction}

A recent shift from predominantly thicker, older multi-year sea ice (MYI) to thinner, smoother first-year sea ice (FYI) has occurred in response to atmospheric and oceanic warming in the Arctic (Perovich et al., 2007; Kwok et al., 2009). With this change has come an increasing presence of melt ponds (hereafter ponds) on the ice during spring and summer, as a relative lack of topography on FYI compared to MYI promotes the spreading of ponds over a greater area (Eicken et al., 2004). Ponds have a considerably lower albedo than bare sea ice, enhancing the melting rate at the ice surface and within the ice interior (Morassutti and Ledrew, 1996; Hanesiak et al., 2001a; Perovich et al., 2003; Holland et al., 2012). Understanding the processes and feedbacks associated with the timing of pond formation and evolution of pond fraction $\left(f_{\mathrm{p}}\right)$ has become the subject of much interest within a multidisciplinary context.

Regional- and basin-scale quantification of sea ice pond properties first requires improvements to satellite retrievals (IGOS, 2007), though approaches are hindered by the subscale and spectrally variant nature of pond-covered sea ice. Thresholding, spectral unmixing, principal components analysis and artificial neural network approaches have been applied to optical data from Landsat 7 and Moderate Resolution Imaging Spectroradiometer (MODIS) scenes to derive estimates of $f_{\mathrm{p}}$ from mixed pixels (Markus et al., 2003; Tschudi et al., 2008; Rösel and Kaleschke, 2011; Rösel et al., 2012). The latter approach was applied to the MODIS data record for years 2000-2011, enabling the study of anomalies in basin-wide $f_{\mathrm{p}}$ over that period (Rösel and Kaleschke, 2012). However, ubiquitous cloud cover over the Arctic 
duringsummer prevents the application of this approach on timescales commensurate with intra-seasonal $f_{\mathrm{p}}$ variations. Efforts to minimise errors caused by variations in spectral reflection are also on-going (Zege et al., 2012). Satellite passive microwave radiometer and active scatterometer data, acquired independently of cloud cover, have shown promise for identifying seasonal transitions associated with pond formation and drainage (Belchansky et al., 2005; Howell et al., 2006). Their utility lie in the sensitivity of emission or backscatter signals to the occurrence of free water on the ice surface (Hallikainen and Winebrenner, 1992). Unfortunately, detection algorithms are limited by coarse (kilometre-scale) spatial resolutions, so that signal confusion is caused by the opening of leads and polynyas due to summer melt and divergent ice motion (Heygster et al., 2012).

Satellite synthetic aperture radar (SAR) is an all-weather, active, microwave remote-sensing tool with an established legacy of high spatial resolution (metre-scale) observations of sea ice. Satellites SARs ERS-1/2 (European Remote Sensing), Radarsat-1/2 and Envisat-ASAR (Environmental Satellite-Advanced Synthetic Aperture Radar) have provided C-band frequency radar data since 1991 that have been used for regional-scale scientific studies and operational observations of ice types, dynamics and thermodynamic evolution. A categorisation of sea ice thermodynamic states and related SAR backscatter regimes, denoted fall freeze-up, winter, spring early melt, melt onset, and summer advanced melt, has been well defined for single-polarisation (VV or $\mathrm{HH}$ ) Cband SAR, except for during advanced melt (Livingstone et al., 1987; Barber et al., 1995; Yackel at al., 2007). During advanced melt, when ponding occurs, variable wind stress on pond surfaces causes surface roughness and backscatter intensity fluctuations which are further affected by variations in $f_{\mathrm{p}}$ within a resolution cell (Barber and Yackel, 1999; Yackel and Barber, 2000). The presence of calm, specular ponds, combined with high $f_{\mathrm{p}}$, exacerbates the possibility of backscatter that is noise floor contaminated particularly at high incidence angles (De Abreu et al., 2001).

In contrast to single-polarisation backscatter, the $\mathrm{VV} / \mathrm{HH}$ ratio enables uncertainty caused by surface roughness to be minimised. According to the Bragg scattering theory, $\mathrm{VV} / \mathrm{HH}$ is independent of surface roughness provided $k s<0.3$, where $k$ is the radar wave number and $s$ the root mean square (rms) surface height (Fung, 1994). VV/HH from a Bragg surface also increases with incidence angle, $\theta$, at a rate determined by the surface complex dielectric permittivity:

$\varepsilon_{\mathrm{r}}=\varepsilon^{\prime}+i \varepsilon^{\prime \prime}$,

where $\varepsilon^{\prime}$ and $\varepsilon^{\prime \prime}$ are real and imaginary parts, respectively, and $i=\sqrt{-1}$. Studies of C-band $\mathrm{VV} / \mathrm{HH}$ from airborne and satellite SAR imagery have demonstrated its utility for separating FYI and MYI from young ice, leads and open water during the winter season (Thomsen et al., 1998; Scheuchl et al., 2004; Nghiem and Bertoia, 2001; Geldsetzer and Yackel,
2009). Separation is based on higher VV/HH from saline young ice and free water in leads and ocean, compared to mature and low salinity ice types, due to higher $\varepsilon_{\mathrm{r}}$. Correlations between winter sea ice thickness and bulk salinity have pointed to the utility of C-band VV/HH for proxy thickness estimates (Zabel et al., 1996; Nakamura et al., 2009). Recently, VV/HH has been assessed for resolving horizontally distributed dielectric mixtures such as oil within a sea ice environment (Brekke et al., 2013).

Scharien et al. (2007) observed Bragg-like behaviour in Cband Envisat-ASAR alternating polarisation images of pondcovered level FYI taken at large $\theta\left(>40^{\circ}\right)$. They found the surface albedo from a horizontally distributed mixture of pond and ice can be estimated with much greater accuracy using $\mathrm{VV} / \mathrm{HH}$, compared to individual co-polarisation channels, due to the sensitivity of the ratio to the high $\varepsilon_{\mathrm{r}}$ of ponds. Scharien et al. (2012) utilised in situ polarimetric C-band scatterometer measurements of individual pond and bare ice patches on level FYI, and demonstrated a large VV/HH from pond compared to ice when $\theta \geq 35^{\circ}$. Note that we consider it more appropriate to hypothesise that, at a fixed $\theta$ beyond $35^{\circ}$, the magnitude of $\mathrm{VV} / \mathrm{HH}$ is sensitive to $f_{\mathrm{p}}$ instead of albedo. This consideration is made on the basis that ponds are purely surface scattering, so that $\mathrm{VV} / \mathrm{HH}$ response is based on presence or absence of pond water and not variations in albedo, which can be significant (Morassutti and Ledrew, 1996; Haneksiak et al., 2001b).

The advantage of using $\mathrm{VV} / \mathrm{HH}$ from a Bragg surface is the retrieval of pond information (timing of pond formation, $f_{\mathrm{p}}$ evolution and drainage) without the need for auxiliary wind speed or surface roughness data. However, at C-band frequency most natural surfaces fall beyond the smooth surface roughness limit imposed by the model (Hajnsek et al., 2003). When the limit is exceeded, or volume scattering occurs, polarisation diversity is lost and $\mathrm{VV} / \mathrm{HH}$ tends to unity. While Scharien et al. (2007) assumed Bragg scattering, Scharien et al. (2012) found poor agreement between $\mathrm{VV} / \mathrm{HH}$ measurements and Bragg model estimates. Reductions in $\mathrm{VV} / \mathrm{HH}$, consistent with non-Bragg scattering, were also observed in the latter study during periods of high wind stress on ponds. This highlights the need for more work defining the radar-scale surface roughness characteristics of pond-covered sea ice and, in terms of scattering theory, an extension to models with a wider domain of validity. The surface-scattering integral equation model (IEM) is appropriate for assessing the scattering behaviour of pondcovered sea ice (Fung, 1994). With the transition model for the Fresnel reflection coefficients (Wu et al., 2001), the IEM is valid for rougher surfaces with validity limits of $k s<2$ and rms slope $<0.4$. However, the IEM is dependent on surface roughness at all scales, and its application to SAR retrievals of surface features, such as soil moisture content, requires empirical calibration (Baghdadi et al., 2004; Zribi et al., 2006). 
This paper presents in situ surface roughness and C-band scatterometer measurements made on level, landfast FYI in the Canadian Arctic Archipelago (CAA) during advanced melt. In situ measurements form part of a larger study focused on understanding the multi-scale C-band backscatter properties of pond-covered sea ice. Here, we document the surface roughness characteristics of ponds and level FYI and compare microwave-scattering model simulations of $\mathrm{VV} / \mathrm{HH}$ to scatterometer measurements. Emphasis is placed on $\mathrm{VV} / \mathrm{HH}$, though single-polarisation channels (VV, $\mathrm{HH}$, and $\mathrm{HV}$ ) and the $\mathrm{HV} / \mathrm{HH}$ ratio are also considered as potential complementary or standalone parameters within a SAR imaging context. The following research questions are addressed: (1) what are the radar-scale surface roughness characteristics of ponds and ice on level FYI? (2) What is the appropriate scattering model for simulations of pond-covered level FYI? (3) What are the limiting radar and target parameters on the unambiguous retrieval of pond information from dual-polarisation C-band SAR? Questions (1) and (2) focus on the characterisation of surface roughness in relation to the validity domains of the Bragg and IEM scattering models, while question (3) considers the suite of dual-polarisation scatterometer measurements of pond and ice features. It is worth noting that, despite collecting fully polarimetric scatterometer data, our focus is limited to dual-polarisation Cband radar, since the availability of polarimetric SAR data is severely limited.

In Sect. 2 we present our working conceptual model of the radar and target parameters affecting microwave scattering from level FYI during ponding. An overview of the study area, the data set and methods are presented in Sect. 3. Results are provided in Sect. 4, beginning with a description of the nature of the ice cover (Sect. 4.1) and followed by surface roughness characterisation (Sect. 4.2). Experimental radar data and theoretical scattering model simulations are assessed in Sect. 4.3. In Sect. 5 we discuss possible error sources in the collection of surface roughness data (Sect. 5.1), and potential limits to the retrieval of sea ice melt pond information from SAR (Sect. 5.2). In Sect. 6 our concluding statements are given. This provides the basis for Part 2 (Scharien et al., 2014), which extends the in situ results to the satellite SAR scale using calibrated Radarsat-2 SAR data.

\section{Physical model}

The ensemble of radar and target parameters considered in the analysis of backscatter from level FYI during ponding is shown in Fig. 1. In our case the radar parameters of interest are constrained by our in situ scatterometer and interest in dual-polarisation C-band SAR. Constraints on the viewing geometry of the radar include $\theta$ and azimuth direction, $\phi$. Determining the role of $\phi$ on backscatter from ponds in important given observations from the ocean which show a

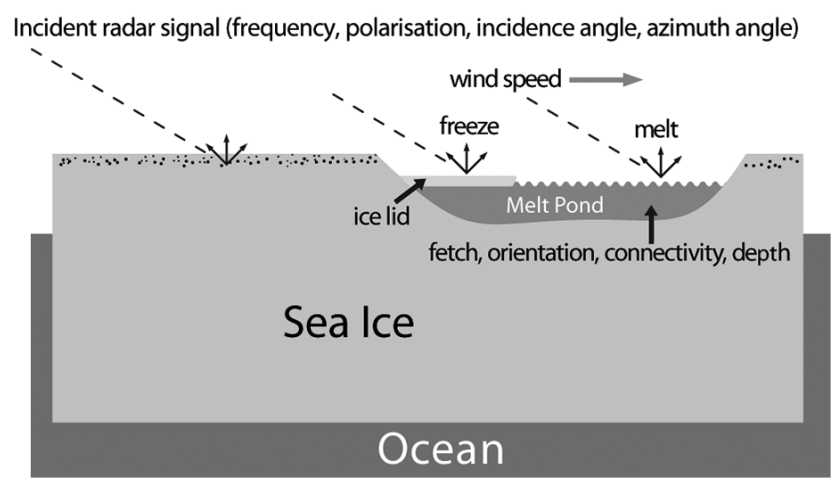

Figure 1. Schematisation of the radar and target parameters under consideration for the in situ study of microwave backscatter from a snow-free level first-year sea ice during ponding.

strong dependency of backscatter on radar orientation relative to wind waves. Backscatter is strongest when the radar beam is aligned upwind and perpendicular to wind waves $\left(\phi=0^{\circ}\right)$, and weakest when aligned crosswind and parallel to wind waves $\left(\phi=90^{\circ}\right)$ (Ulaby et al., 1986). While VV, HH and $\mathrm{HV}$ backscatter from ponds are expected to vary with $\phi$, behaviour of $\mathrm{VV} / \mathrm{HH}$ and $\mathrm{HV} / \mathrm{HH}$ is uncertain. In particular, independence of $\mathrm{VV} / \mathrm{HH}$ from roughness under the Bragg theory would also mean independence from $\phi$, which is desirable when considering the possibility of SAR-based retrievals.

Surface parameters in Fig. 1 are primarily linked to the net surface energy balance. Ponds are very close to the triple point of water, such that their phase state is intrinsically related to $s$ and $\varepsilon_{\mathrm{r}}$ (Barber and Yackel, 1999). A positive energy balance at the pond surface yields free water which is subject to wave development through wind stress, whereas a negative energy balance causes a relatively smooth, typically $1-2 \mathrm{~cm}$, ice lid to form on the pond surface. Free water is subject to wind-wave growth, which is enhanced by wind speed and fetch. It follows that ponds, when oriented so that their long axes are parallel to the wind direction, will have larger $s$. Connectivity, or the channelling between ponds that occurs on FYI (Eicken et al., 2002) will also increase the effective fetch and wave growth by facilitating the transfer of wind-wave energy between ponds. Pond depth has been shown to explain a significant portion of single-polarisation C-band backscatter variability from FYI ponds (Scharien et al., 2012), though the relationship was linked to wave damping by bottom friction in shallow ponds $(\leq 3 \mathrm{~cm})$, not the growth of wind waves with increasing depth. Ice lids may form during the diurnal solar minimum (Yackel et al., 2007) or when a clearing of low level stratus cloud cover causes a sudden loss of long-wave energy to the atmosphere (Untersteiner, 2004). These lids act to suppress the wind-wave surface roughness effects associated with free water.

FYI during ponding is predominantly surface scattering; however, centimetre-scale penetration depths at C-band 
frequency and volume scattering from voids and air bubbles in desalinated layers have been shown to occur (Scharien et al., 2010). Volume scattering is also linked to the surface energy balance, with enhanced single-polarisation backscatter intensities during either freezing periods, or melting periods when melt water is readily drained from the upper layer of the ice. The model in Fig. 1 does not consider a meteoric snow cover despite its possible presence during the initial pond formation period. On FYI snow cover melt contributes to pond formation before completely decaying over a period of no more than 1 week (Barber and Yackel, 1999; Eicken et al., 2002; Scharien and Yackel, 2005; Polashenski et al., 2012). Variations in snow moisture content are expected to influence backscatter and polarisation ratios when snow is present during ponding. However, during our in situ study there remained no snow cover when sampling commenced, so we consider bare ice only.

\section{Methods}

\subsection{Description of the study area}

Data were collected during the Arctic-Ice Covered Ecosystem (Arctic-ICE) field project on level FYI landfast within the CAA, near the hamlet of Resolute Bay, from May to July 2012 (Fig. 2, left). Arctic-ICE is an interdisciplinary project with focus on biogeochemical and physical processes occurring at the ocean-sea ice-atmosphere (OSA) interface during the spring-summer snow melt and ponding periods. Studies are conducted on level and landfast FYI as it provides a stable platform from which to conduct co-located time series in situ and remote-sensing sea ice measurements without the influence of ice deformation or dynamic processes. References to ice hereafter apply to this ice type unless otherwise noted.

\subsection{Data collection}

Polarimetric backscatter measurements from elemental surface types bare ice and ponds were collected at the ArcticICE field site using a sled-mounted C-band frequency scatterometer (Cscat) operating at $2.4 \mathrm{~m}$ height (Fig. 2, top right). Cscat radar parameters are provided in Table 1 with details on standardised calibration, data processing and accuracy determination (contributions of random, bias and residual error terms) are found in Geldsetzer et al. (2007). The low noise floor of the Cscat, $-35 \mathrm{~dB}$ for co-polarised and $-45 \mathrm{~dB}$ for cross-polarised channels, makes it ideal for studying low intensity targets such as summer sea ice. After calibration, the absolute accuracy of co- and cross-polarised backscatter is estimated to be \pm 1.8 to $2.4 \mathrm{~dB}$. Error is reduced at high $\theta$ since the beam is spread wider, resulting in the collection of more independent samples $\left(N_{\text {ind }}\right)$ or data blocks making up the average for that scan line. In the field, the Cscat was towed by a snow machine, and a computer controlledtracking
Table 1. Scatterometer radar parameters.

\begin{tabular}{ll}
\hline Parameter & Specification \\
\hline Frequency & $5.5 \mathrm{GHz}$ (C-band) \\
Antenna beam width & $5.4^{\circ}$ \\
Bandwidth & $5-500 \mathrm{MHz}$ \\
Range resolution & $0.30 \mathrm{~m}$ \\
Polarisation & $\mathrm{HH}+\mathrm{HV}+\mathrm{VH}+\mathrm{VV}$ \\
Noise floor & Co-polarised: $-35 \mathrm{~dB}$ \\
& Cross-polarised: $-45 \mathrm{~dB}$ \\
Incidence angle & $25-65^{\circ}\left(5^{\circ}\right.$ interval $)$ \\
Azimuthal width & Ice: $40^{\circ}$ melt pond: $20^{\circ}$ \\
External calibration & Trihedral corner reflector \\
\hline
\end{tabular}

Table 2. Scatterometer scans of discrete features collected between 16 and 24 June 2012 on level first-year sea ice at the Arctic-ICE study site, including total number of independent samples $\left(N_{\text {ind }}\right)$ for each feature.

\begin{tabular}{lrr}
\hline Feature & Scans & $N_{\text {ind }}$ \\
\hline Bare ice & 49 & 8869 \\
Melt pond, $\phi=0^{\circ}$ & 140 & 19880 \\
Melt pond, $\phi \neq 0^{\circ}$ & 17 & 2414 \\
Melt pond, ice lid & 4 & 568 \\
\hline
\end{tabular}

and positioning system was used to isolate homogeneous targets over a small $\left(<10 \mathrm{~m}^{2}\right)$ footprint. Each scan involved the collection of polarimetric backscatter over the 25 to $65^{\circ} \theta$ range at $5^{\circ}$ increments, though near-range $\theta$ was sometimes greater in order to avoid overlap between pond and ice at the pond edge. Azimuthal widths of 20 and $40^{\circ}$ were used for pond and ice scans, respectively, with the smaller width for ponds used to focus the radar beam to $\phi$-specific orientations, e.g. upwind or crosswind. A total of 210 Cscat scans collected between 16 and 24 June were output to a database comprised of $\theta$ dependent backscatter in average covariance matrix format, classed by cover type (Table 2).

Pond Cscat scans were synched with $1 \mathrm{~m}$ wind speed data collected at $1 \mathrm{~s}$ resolution using a tripod-mounted RM-Young 05103 wind monitor positioned adjacent to the scanned area and away from potential interference by the Cscat and other equipment. Wind speed measurements were adjusted to neutral stability values at a reference $10 \mathrm{~m}$ height, $U_{10}$, using the aerodynamic roughness length of $0.001 \mathrm{~m}$ for summer sea ice (Andreas et al., 2005).

Small-scale surface roughness measurements of the snowcovered ice during melt onset, and bare ice during ponding, were made from 6 to 25 June using a high-resolution terrestrial laser scanning (or lidar) system, following Landy et al. (2014). Data from melt onset is included to provide context for assessing the evolution of surface from melting snow to bare ice. The scanner was mounted on a tripod and configured to acquire several $3.5 \mathrm{~m} \times 3.5 \mathrm{~m}$ elevation 


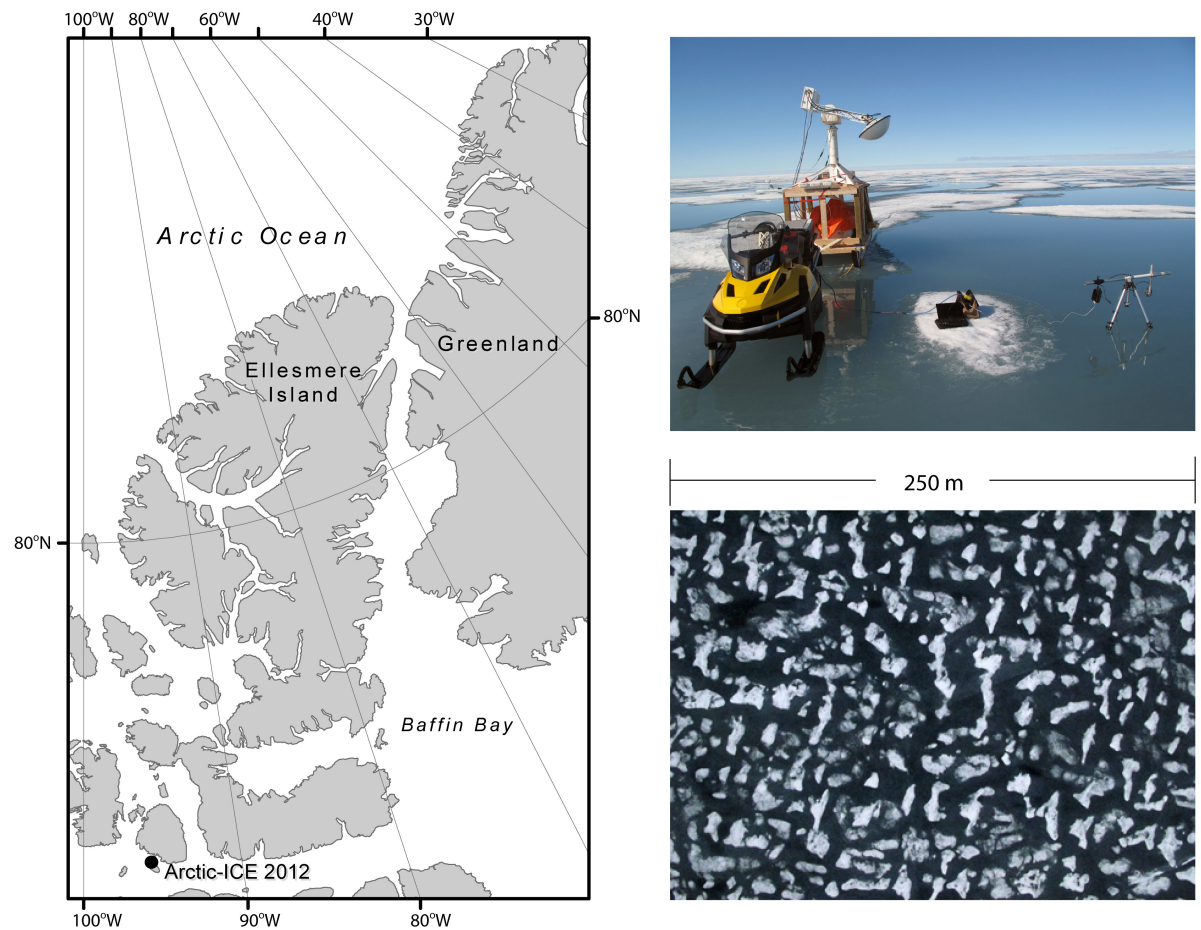

Figure 2. (Left) Map showing the location of the Arctic-ICE 2012 field study site in the central Canadian Arctic Archipelago. (Upper right) Oblique view of pond-covered level first-year sea ice with C-band frequency scatterometer (Cscat) and tripod-mounted ultrasonic sensor in the pond. In this configuration the wind is blowing from right to left across the photo. (Lower right) Aerial photo showing Nadir view of the study site on 24 June 2012, taken at $210 \mathrm{~m}$ altitude and covering a $250 \mathrm{~m}$ wide swath.

modelscoincident to Cscat scans at a measurement spacing of $<2 \mathrm{~mm}$. Pond surface wave height profiles were collected as part of a larger study examining air-water interactions using a Senix Corporation ToughSonic ${ }^{\circledR}$ type TPSC30S1 ultrasonic distance sensor with $0.086 \mathrm{~mm}$ resolution and $0.2 \%$ range repeatability error. It was mounted to an adjustable, counter-weighted, boom arm extending between 0.5 and $1 \mathrm{~m}$ laterally from a tripod placed adjacent to, or within, a Cscat footprint after scanning (Fig. 2, top right). Profiles of $30 \mathrm{~s} \mathrm{du}-$ ration were captured at a $40 \mathrm{~Hz}$ sampling rate, coincident to $1 \mathrm{~s}$ wind speed data collected at $1 \mathrm{~m}$ height (also converted to $U_{10}$ ).

Ancillary data include daily measurements of snow and ice thickness, and vertical profiles of temperature, salinity and density through melt onset and ponding periods. Snow volumetric moisture content measurements were made using the impedance probe and inversion method described in Scharien et al. (2010). Hourly air temperature (2 m) and wind speed/direction $(3 \mathrm{~m})$ are derived from instrumentation mounted to the ice-based Arctic-ICE micrometeorological tower. Additional pond morphological measurements include transects of pond depth at $0.5 \mathrm{~m}$ horizontal spacing, fetch lengths and minor/major axis lengths. The connectivity between ponds was qualitatively assessed using a combination of surface and aerial photographs (e.g. Fig. 2, bottom right). Details on the aerial photography program, which included surveys of $f_{\mathrm{p}}$ coincident to Radarsat-2 SAR image acquisitions, are provided in Part 2.

\subsection{Post processing and partitioning of backscatter data}

From the Cscat database HH, VV and HV backscatter, and $\mathrm{VV} / \mathrm{HH}$ and $\mathrm{HV} / \mathrm{HH}$ backscatter ratios were calculated. $\mathrm{VH}$ backscatter was not considered under the assumption of reciprocity $(\mathrm{VH}=\mathrm{HV})$. Radiometric quality control involved the removal of individual scan lines within each scan that had a signal to noise ratio $(\mathrm{SNR})<5$. These were typically measurements from calm, specular, ponds or those made at high $\theta$.

For investigating the role of target parameters on backscatter from ponds, the 140 samples taken with $\phi=0^{\circ}$, hereafter Database A, were used. This configuration corresponds with the aforementioned maximum backscatter sensitivity (Ulaby et al., 1986) and provides a control for $\phi$ against which to assess the influence of target parameters. For comparison to scattering model simulations, the 17 backscatter samples of ponds taken with $\phi \neq 0^{\circ}$, hereafter Database B, were used. While this partitioning yields fewer samples for model comparison, it removes the considerable effect that bound, tilted waves on the leeward face of wind waves have on measured $\mathrm{VV} / \mathrm{HH}$ (Plant et al., 1999). These features cause a large reduction in $\mathrm{VV} / \mathrm{HH}$ by decreasing the local $\theta$ in the upwind 
case; Plant et al. (1999) observed a $\geq 4 \mathrm{~dB}$ decrease at $45^{\circ} \theta$ from wind-wave tank measurements. It is reasonable to assume this effect is unlikely to be encountered when imaging pond-covered ice by SAR.

To further investigate the role of $\phi$ on pond $\mathrm{VV} / \mathrm{HH}$ and $\mathrm{HV} / \mathrm{HH}$, cases which included replicate samples made in the same pond at $\phi=0^{\circ}$ and $\phi=90^{\circ}$ configurations, hereafter Database $\mathrm{C}$, were used. Importantly there was negligible change in $U_{10}$ during sampling. A $30 \mathrm{~s}$ wind-synched pond surface wave amplitude profile was recorded close to the Cscat footprint during each case. From the backscatter data, the crosswind to upwind ratio was calculated:

$$
\Delta \mathrm{VV} / \mathrm{HH}=\overline{\mathrm{VV} / \mathrm{HH}} \cdot \varphi=0^{\circ}-\overline{\mathrm{VV} / \mathrm{HH}} \cdot \varphi=90^{\circ}(\mathrm{dB}),
$$

with the calculation repeated for $\mathrm{HV} / \mathrm{HH}$ in place of $\mathrm{VV} / \mathrm{HH}$. Equation (2) was evaluated at $5^{\circ}$ intervals between the range $35^{\circ} \leq \theta \leq 50^{\circ}$. The lower limit for $\theta$ corresponds to the approximate lower bound where the separation between $\mathrm{VV}$ and $\mathrm{HH}$ from ponds begins, whereas the upper limit for $\theta$ was constrained by the availability of data above the system noise equivalent sigma zero (NESZ).

Ice surface roughness data were derived from lidar models, which were resampled to a regular $2 \mathrm{~mm}$ grid and detrended using a fast Fourier transform-based technique to remove large-scale ice topography. Roughness parameters rms height $\left(s_{i}\right)$, and correlation length $\left(l_{i}\right)$ were then extracted using the two-dimensional auto-correlation technique outlined in Landy et al. (2014). We examined the form of the autocorrelation function (ACF) and tested it against the exponential and Gaussian models, and a generalised powerlaw model where the exponent of the power-law function, $n,(1<n<2)$, lies between exponential $(n=1)$ and Gaussian $(n=2)$ forms. Each model was fit to hundreds of radial profiles across the two-dimensional ACF from each of the $3.5 \mathrm{~m} \times 3.5 \mathrm{~m}$ elevation models and the average coefficient of determination $\left(r^{2}\right)$ between observations and models was determined along with the mean of $n$. Since the experimental ACF generally begins to oscillate after several correlation lengths, as the correlation approaches zero, we restricted the model fit to a lag distance of $3 l_{i}$.

The first step in processing pond wave height profile data for roughness characterisation involved discarding profiles with coincident $U_{10} \leq 4 \mathrm{~m} \mathrm{~s}^{-1}$. This cut-off was based on the wave height spectra of FYI melt pond wind waves reported by Scharien and Yackel (2005), which showed dominant wavelengths of $\sim 0.21-0.31 \mathrm{~m}$ at $U_{10} \geq 4 \mathrm{~m} \mathrm{~s}^{-1}$. By removing profiles at small $U_{10}$ we increase the likelihood that wind waves are much larger than the estimated transducer spot size of 0.04 , and measured echo returns are from a pure target (wave peak or trough). In all, 43 profiles were retained for analysis and subsampled to $8 \mathrm{~Hz}$, from which pond surface rms height $\left(s_{\mathrm{W}}\right)$, correlation length $\left(l_{\mathrm{w}}\right)$ and wave height spectra were derived. Here $l_{\mathrm{w}}$ is derived from the time in lags at which the ACF of profile falls to $1 / \varepsilon(1 \mathrm{lag}$ is $0.125 \mathrm{~s}$ at
$8 \mathrm{~Hz}$ ), multiplied by the estimated phase speed of the dominant wave from the peak frequency of the corresponding wave height spectrum. The form of the ACF and $n$ were found for each of the 1-D wave profiles as described above for ice roughness data.

\subsection{Comparison to backscattering theory}

Surface backscattering from ice and pond cover types was modelled using the IEM (Fung, 1994):

$\sigma_{p p}^{\circ}=\frac{k^{2}}{2} \exp \left(-2 k_{z}^{2} s^{2}\right) \sum_{n=1}^{\infty} s^{2 n}\left|I_{p p}^{n}\right|^{2} \frac{W^{(n)}\left(-2 k_{x}, 0\right)}{n !}$,

where $k_{z}=k \cos \theta, k_{x}=k \sin \theta$ and $p p=\mathrm{VV}$ or $\mathrm{HH}$,

$$
\begin{aligned}
I_{p p}^{n} & \left.=\left(2 k_{z} s\right)^{n} f_{p p} \exp \left(-k_{z}^{2} s^{2}\right)\right] \\
& +\frac{\left(k_{z} s\right)^{n}\left[F_{p p}\left(-k_{x}, 0\right)+F_{p p}\left(k_{x}, 0\right)\right]}{2},
\end{aligned}
$$

and $W^{(n)}\left(-2 k_{x}, 0\right)$ is the Fourier transform of the $n$th power of the surface ACF. The form of the ACF was determined by in situ data in Sect. 4.2.

Additional coefficients for the model are as follows:

$$
f_{\mathrm{VV}}=\frac{2 R_{\|}}{\cos \theta} ; f_{\mathrm{HH}}=\frac{2 R_{\perp}}{\cos \theta},
$$

$$
\begin{aligned}
& F_{\mathrm{VV}}\left(-k_{x}, 0\right)+F_{\mathrm{VV}}\left(k_{x}, 0\right)=\frac{2 \sin ^{2} \theta\left(1+R_{\|}\right)^{2}}{\cos \theta} \\
& {\left[\left(1-\frac{1}{\varepsilon_{\mathrm{r}}}\right)+\frac{\mu_{\mathrm{r}} \varepsilon_{\mathrm{r}}-\sin ^{2} \theta-\varepsilon_{\mathrm{r}} \cos ^{2} \theta}{\varepsilon_{\mathrm{r}}^{2} \cos ^{2} \theta}\right],}
\end{aligned}
$$

$$
\begin{aligned}
& F_{\mathrm{HH}}\left(-k_{x}, 0\right)+F_{\mathrm{HH}}\left(k_{x}, 0\right)=\frac{2 \sin ^{2} \theta\left(1+R_{\perp}\right)^{2}}{\cos \theta} \\
& {\left[\left(1-\frac{1}{\varepsilon_{\mathrm{r}}}\right)+\frac{\mu_{\mathrm{r}} \varepsilon_{\mathrm{r}}-\sin ^{2} \theta-\varepsilon_{\mathrm{r}} \cos ^{2} \theta}{\mu_{\mathrm{r}}^{2} \cos ^{2} \theta}\right],}
\end{aligned}
$$

where $\mu_{\mathrm{r}}$ is the relative permeability and $R_{\|}, R \perp$ are the Fresnel reflection coefficients for $\mathrm{H}$ and $\mathrm{V}$ polarisations.

We estimated the input $\varepsilon_{\mathrm{r}}$ values for pond and ice used in the IEM. A pond $\varepsilon_{\mathrm{r}}$ of $67.03+35.96 i$ was determined by solving the frequency and temperature dependent Debye equation for fresh water, using a $5.5 \mathrm{GHz}$ frequency and assumed temperature of $0.5^{\circ} \mathrm{C}$ (Ulaby et al., 1986). Upper and lower bounds of $\varepsilon_{\mathrm{r}}$ representing bare ice cover in cold/dry and warm/wet conditions were estimated. The lower bound $\varepsilon_{\mathrm{r}}$ of $1.95+0.003 i$ was estimated by combining a simple two-phase (pure ice and air) Polder-Van Santen mixing formula for the real part, and an empirical fit to experimental data for the imaginary part (Ulaby et al., 1986). The upper bound of $3.11+0.208 i$ was established using the Mätzler mixing formula approach for water inclusions (Mätzler et 


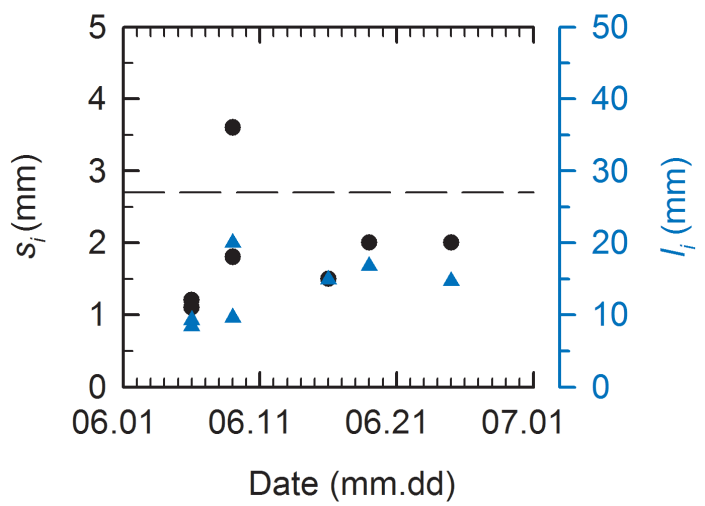

Figure 3. Time series surface rms height $s_{i}$ and correlation length $l_{\mathrm{i}}$ of level first-year sea ice during melt onset and ponding periods. Melt ponds formed on 13 June. The dashed line denotes the upper limit of the Bragg model validity range at $\mathrm{C}$-band frequency.

al., 1984; Drinkwater and Crocker, 1988), with the maximum in situ measured volumetric moisture content of $7 \%$ for the near-surface layer of level FYI during ponding (Scharien et al., 2010) used to initiate the model. In either case, the ice cover was assumed to be low density $\left(500 \mathrm{~kg} \mathrm{~m}^{-3}\right)$ and devoid of brine when estimating $\varepsilon_{\mathrm{r}}$.

\section{Results}

\subsection{Description of the sea ice cover}

During melt onset air temperature was $>0{ }^{\circ} \mathrm{C}$ except for a few brief overnight periods where it was below freezing but remained $\geq-1.1^{\circ} \mathrm{C}$. The snow cover was $<10 \mathrm{~cm}$ thick, isothermal and had no salinity. Mean snow density was $<200 \mathrm{~kg} \mathrm{~m}^{-3}$ and volumetric moisture content ranged from 3 to $4 \%$. Layer stratigraphy indicated melt-freeze metamorphosed grains increasing in size with depth to centimetrescale grains overlying a basal slush layer. Basal slush layer re-freezing and the formation of a rough superimposed ice layer with centimetre-scale undulations were observed for some snow patches. By 12 June only sporadic patches of snow with $3 \mathrm{~cm}$ maximum depth overlying rough basal layers remained. During melt onset the top $0.10 \mathrm{~m}$ of the ice became isothermal and its salinity reduced from 1.7 to $0.5 \%$.

A storm event on 13 June, including strong winds and rain, caused the obliteration of the snow and rough basal layer patches and coincided with the beginning of ponding. During ponding, pond depths ranged from 0.03 to $0.08 \mathrm{~m}$. Pond depth was not observed to increase with time, rather variations were consistent with a balancing of melting and drainage rates at any one time (Eicken et al., 2002). Pond aspect ratio, the ratio of minor and major axis lengths, was $0.2-0.7$ (mean 0.5). Elongated ponds indicate enhanced fetch when the wind direction is parallel to their long axes. As illustrated by the aerial photo in Fig. 2, connectivity between
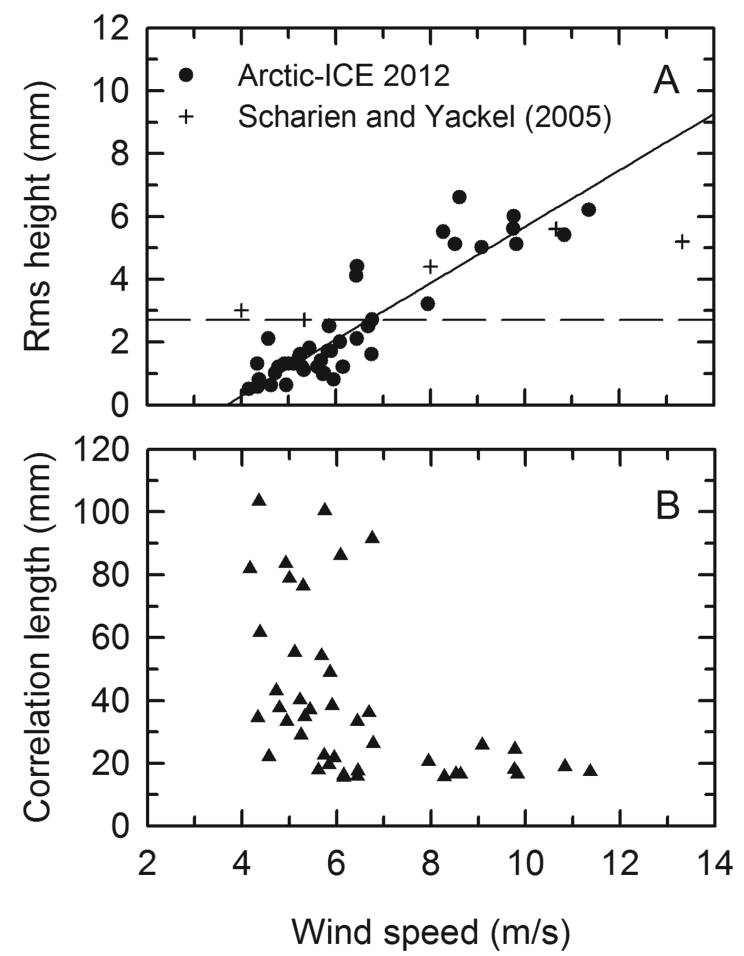

Figure 4. Wind speed $\left(U_{10}\right)$ dependencies of surface rms height (a) and correlation length (b) for melt ponds on level first-year sea ice. Included in (a) are rms height measurements from the wave imaging technique described in Scharien and Yackel (2005). The dashed line in (a) denotes the upper limit of the Bragg model validity range at C-band frequency.

ponds also indicates the potential for enhanced fetch or, similarly, less wave energy dissipation when the wind direction is aligned with pathways joining ponds. Cscat and pond windwave profile measurements were made at fetch lengths covering the 7.8 to $34.8 \mathrm{~m}$ range. During ponding the top 0.10 of the bare ice ranged in salinity from 0.5 to $2.3 \%$.

\subsection{Surface roughness}

Figure 3 shows that ice surface roughness is within the Bragg region, except for one observation on 9 June when a rough superimposed basal layer was measured after careful removal of the snow cover. During ponding bare ice $\overline{s_{\mathrm{i}}}=1.9 \mathrm{~mm}, \overline{l_{\mathrm{i}}}=$ $15.5 \mathrm{~mm}$, ACFs conform to the exponential function $91 \%$ of the time and $n=1.10\left(r^{2}=0.97\right)$. Including melt onset sections, ACFs conform to the exponential function $88 \%$ of the time, producing $n=1.09\left(r^{2}=0.97\right)$. The rough basal layer is unique, showing a 56 to $44 \%$ split between exponential and Gaussian ACFs, respectively, with $n=1.39\left(r^{2}=0.96\right)$. All snow and ice roughness observations fall within the IEM region.

Figure $4 \mathrm{a}$ and $\mathrm{b}$ show the $U_{10}$ dependence of pond $s_{\mathrm{w}}$ and $l_{\mathrm{w}}$, respectively. Figure $4 \mathrm{a}$ also includes wind speed dependent $s_{\mathrm{W}}$, also adjusted to $U_{10}$, for level FYI ponds as reported 

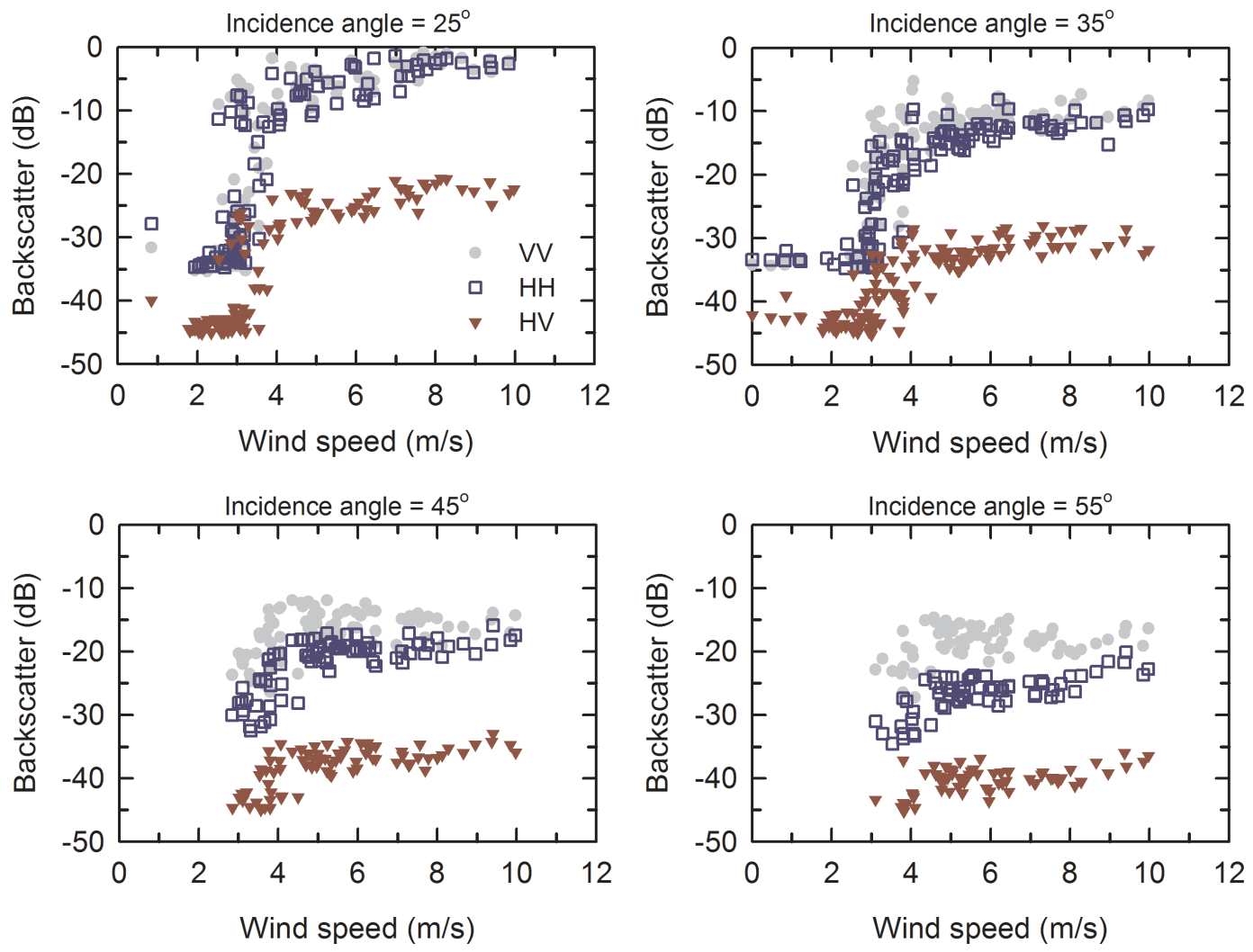

Figure 5. VV, $\mathrm{HH}$ and $\mathrm{HV}$ polarisation backscatter versus wind speed $\left(U_{10}\right)$ at $10^{\circ}$ incidence angle intervals from 25 to $55^{\circ}$. Samples are from Database A.

in Scharien and Yackel (2005). Each point from Scharien and Yackel (2005) in Fig. 4a represents an average $s_{\mathrm{W}}$ of at least 280 wave height profiles extracted from binarized digital images. From the current data set, $s_{\mathrm{w}}$ ranges from 0.5 to $6.6 \mathrm{~mm}$ with $\overline{s_{\mathrm{w}}}=2.5 \mathrm{~mm}$. Roughness values exceeding the Bragg region at $U_{10} \approx 6.4 \mathrm{~m} \mathrm{~s}^{-1}$ were noted to be made during sustained winds parallel to the pathways which interconnected ponds. There are too few data points to purely investigate the point at which the Bragg region is exceeded in relation to connectivity and fetch. Instead, a clustering of $s_{\mathrm{W}}$ values at $U_{10} \geq 8.0 \mathrm{~m} \mathrm{~s}^{-1}$ suggests that the higher wind speeds may be required for pond $s_{\mathrm{W}}$ to exceed the Bragg region when conditions are less favourable to wind-wave growth. Less favourable conditions include periods of minimal wind stress, when ponds are discrete, or when the wind is blowing across minor axes and wave energy dissipation is enhanced. In terms of wind stress, hourly $U_{10}$ obtained from the Arctic-ICE micrometeorological tower showed $U_{10} \geq$ $6.4 \mathrm{~m} \mathrm{~s}^{-1} 20 \%$ of the time, and $U_{10} \geq 8.0 \mathrm{~m} \mathrm{~s}^{-1}$ only $9 \%$ of the time during ponding. Combined with the $s_{\mathrm{W}}$ data these observations suggest that pond roughness is within the Bragg region, and $\mathrm{VV} / \mathrm{HH}$ is independent of roughness, at least $80 \%$ of the time. All pond roughness observations fall within the IEM region.
The $l_{\mathrm{w}}$ in Fig. $4 \mathrm{~b}$ is initially variable, with larger values associated with smooth pond surfaces and low $s_{\mathrm{W}}$. As the surface becomes rougher $l_{\mathrm{w}}$ clusters in the $\sim 15-25 \mathrm{~mm}$ range which is comparable to the ice cover; pond $\overline{l_{\mathrm{w}}}=39.6 \mathrm{~mm}$, the form of the ACF conforms to the exponential function $68 \%$ of the time and $n=1.41$.

\subsection{Measured and modelled backscatter}

\subsubsection{Measured single polarisation backscatter}

Analysis of single polarisation backscatter reveals (1) the singular and relative behaviours of polarisations for changing conditions; and (2) variations in intensity levels which can be compared to the NESZ of imaging SARs. The $U_{10}$ dependencies of VV, HH and HV backscatter from ponds (Database A) are shown in Fig. 5 at $10^{\circ}$ intervals across the range $25^{\circ} \leq \theta \leq 55^{\circ}$. At $U_{10}$ around $3 \mathrm{~m} \mathrm{~s}^{-1}$, a considerable increase in all backscatter magnitudes occurs, particularly at near-range $\theta$ where the increase in $\mathrm{HH}$ and $\mathrm{VV}$ is 20 to $30 \mathrm{~dB}$. Determining the $U_{10}$ threshold at higher $\theta$ is impeded by the loss of low SNR data points during quality control. Allowing for variations due to fetch, connectivity and orientation, the $U_{10}$ threshold near $3 \mathrm{~m} \mathrm{~s}^{-1}$ is consistent with that determined for $\mathrm{C}$-band backscatter from an ocean surface at $0^{\circ} \mathrm{C}$ 


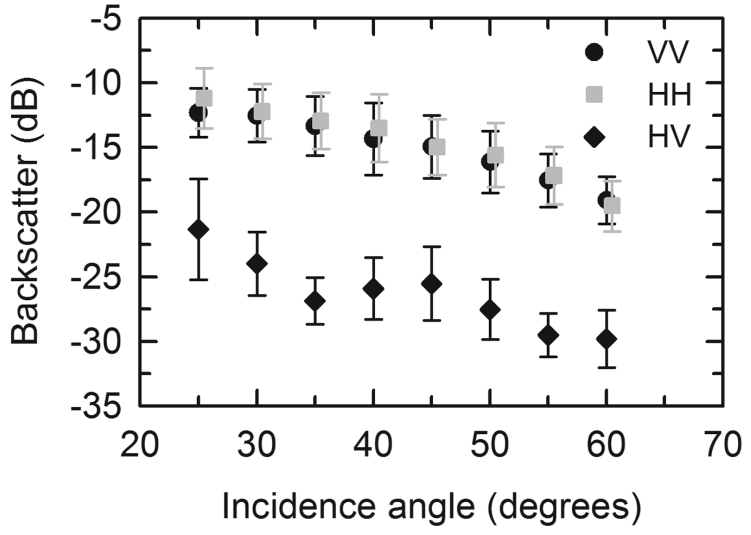

Figure 6. VV, HH and HV polarisation backscatter versus incidence angle, for the bare ice adjacent to melt ponds on level first-year sea ice. Markers for $\mathrm{HH}$ are offset by $+0.5^{\circ}$ to aid in differentiating them from VV. Error bars represent standard deviation.

(Donelan and Pierson, 1987). VV and HH separation with increasing $\theta$ is offset by convergence at higher $U_{10}$. Since we are using Database A, we expect to be observing the maximum effect that wind-wave roughness has on the relative behaviour of VV and $\mathrm{HH}$.

With regard to intensity levels in Fig. 5, the possibility of noise contaminated backscatter when considering SAR generally arises when $U_{10}$ falls below $\sim 3 \mathrm{~m} \mathrm{~s}^{-1}$, or when $\theta \geq 45^{\circ}$. HV is very low, as expected, such that the practical use of SAR measured $\mathrm{HV}$ and $\mathrm{HV} / \mathrm{HH}$ is unlikely except when the system NESZ is also very low. However, the measurements in Fig. 5 represent a pure pond, whereas the potential contribution of bare ice to a mixed return must be considered. Figure 6 shows the $\theta$ dependence of VV, HH and HV (mean and standard deviation) from the 49 measured bare ice samples. VV and $\mathrm{HH}$ are $\geq-17.5 \mathrm{~dB}$ up to $55^{\circ}$ and above the worst case NESZ of SARs Envisat-ASAR, Radarsat-2 and Sentinel-1A (Scheuchl et al., 2004; ESA, 2012). HV measurements of bare ice, as for ponds, are likely to be limited by the NESZ of a SAR.

\subsubsection{Wind speed, direction and pond polarisation ratios}

The $U_{10}$ dependencies of $\mathrm{VV} / \mathrm{HH}$ and $\mathrm{HV} / \mathrm{HH}$ from ponds (Database A) are shown in Fig. 7 at $10^{\circ}$ intervals across the range $25^{\circ} \leq \theta \leq 55^{\circ}$. Above the $\sim 3 \mathrm{~m} \mathrm{~s}^{-1}$ threshold both ratios decrease with increasing $U_{10}$ by several $\mathrm{dB}$. Correlation between $U_{10}$ and each of the polarisation ratios in Fig. 7 was assessed using the Spearman rank-order correlation coefficient. Testing was conducted on sample pairs with $U_{10}>3 \mathrm{~m} \mathrm{~s}^{-1}$ only. All correlations are significant at the $\alpha<0.01$ level. These significant correlations suggest uncertainty in ratio magnitudes due to $U_{10}$. However, we caution that by using Database A (discrete pond with $\phi=0^{\circ}$ ) we are analysing the orientation of maximum expected variation

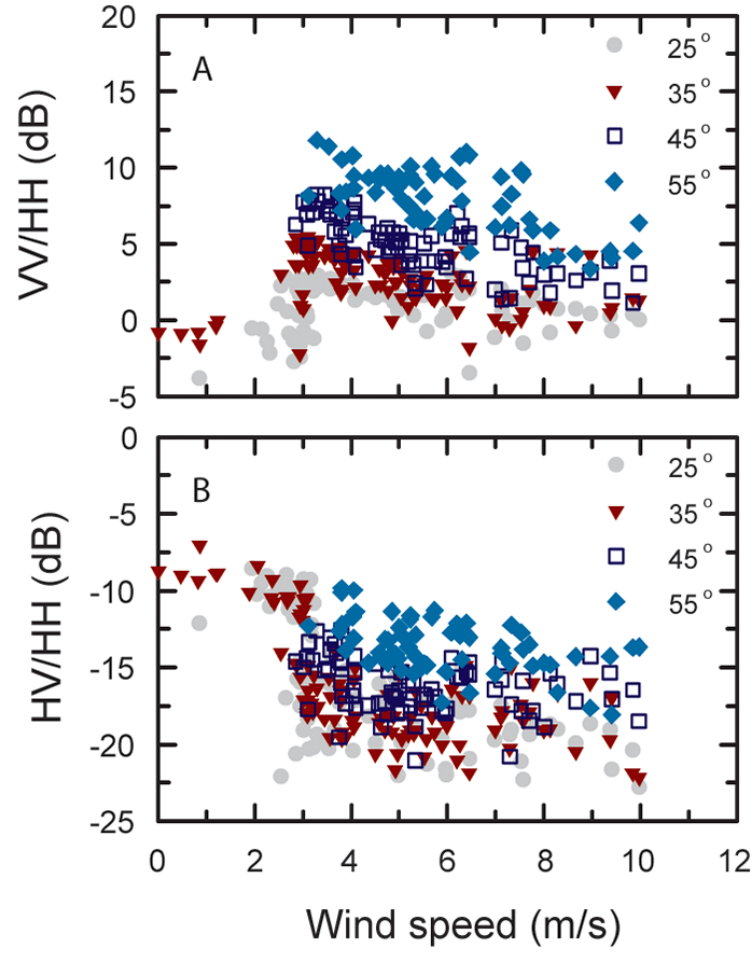

Figure 7. Polarisation ratios $\mathrm{VV} / \mathrm{HH}$ (a) and $\mathrm{HV} / \mathrm{HH}$ (b) versus wind speed $\left(U_{10}\right)$ at $10^{\circ}$ incidence angle intervals from 25 to $55^{\circ}$. Samples were taken from Database A.

due to $U_{10}$. Due to a lack of data points in Database $\mathrm{B}$, correlation testing when $\phi \neq 0^{\circ}$ remains to be established. Instead, the IEM is used in the next section to address the role of $U_{10}$ and wind-wave roughness on $\mathrm{VV} / \mathrm{HH}$ outside of the upwind configuration.

Wind direction dependencies of $\mathrm{VV} / \mathrm{HH}$ and $\mathrm{HV} / \mathrm{HH}$ from ponds (Database $\mathrm{C}$ ) are assessed using the crosswind to upwind ratios for three cases; $A$ to $C$ are given as a function of $\theta$ in Table 3 with coincident $U_{10}, s_{\mathrm{W}}$ and $k s$. The $\mathrm{VV} / \mathrm{HH}$ for the two smoothest $s_{\mathrm{W}}$ cases does not change with a shift in antenna pointing from crosswind to upwind orientations, with the exception of case $A$ at $\theta=35^{\circ}$ which is $\sim 3 \mathrm{~dB}$ larger when $\phi=90^{\circ}$. The $k s$ value for case $A$ is close to the limit of the Bragg region, which likely explains a change from one $\theta$ to the next. The change in $\mathrm{VV} / \mathrm{HH}$ for the roughest case is $\sim 3$ to $4 \mathrm{~dB}$ at all $\theta$, which is consistent with non-Bragg scattering and the emergence of $\mathrm{VV} / \mathrm{HH}$ dependence on roughness and $\phi$. Change in $\mathrm{HV} / \mathrm{HH}$ is consistently $>5 \mathrm{~dB}$ regardless of the roughness condition. Changes in polarisation ratios related to the antenna pointing direction have been undesirable since they suggest the need for ancillary wind information for satellite retrievals; however, as above we expect the effect to be smaller when a pond-covered ice cover is considered rather than discrete melt pond samples. We note the highest $s_{\mathrm{w}}$ in Table 3 is not related to the highest 


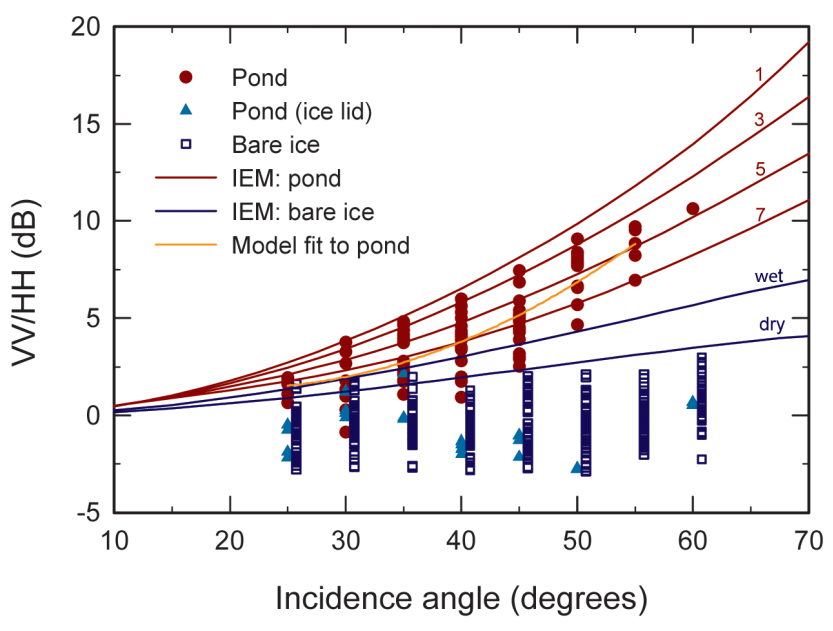

Figure 8. Scatterometer measured $\mathrm{VV} / \mathrm{HH}$ versus incidence angle, from surface types pond, pond (ice lid) and bare ice. Pond samples were taken from Database B. Also shown are IEM simulated $\mathrm{VV} / \mathrm{HH}$ for ponds, with numerical values corresponding to the $s_{\mathrm{W}}$ (in $\mathrm{mm}$ ) used to initiate the model, and $\mathrm{VV} / \mathrm{HH}$ for bare ice under cold/dry and warm/wet conditions. Bare ice observations are offset along the $x$ axis by $1^{\circ}$ for clarity.

$U_{10}$, which indicates the contribution of other factors to pond roughness.

\subsubsection{Polarisation ratio signatures}

Figure 8 shows VV/HH from ponds (Database B), ponds covered by ice lids and bare ice across the interval $25^{\circ} \leq$ $\theta \leq 60^{\circ}$, along with IEM simulations of ponds and ice. Modelling results for ponds are obtained by using a $l_{\mathrm{w}}$ of $40 \mathrm{~mm}$, a power-law ACF with $n=1.41$ and incrementally varying from a smooth $s_{\mathrm{W}}$ of $1 \mathrm{~mm}$ to a rough $s_{\mathrm{W}}$ of $7 \mathrm{~mm}$ based on in situ data from Sect. 4.2. Observed and modelled pond $\mathrm{VV} / \mathrm{HH}$ have generally consistent angular behaviour, though the IEM overestimates VV/HH except at the highest $s_{\mathrm{w}}$. The model predicts a $1-5 \mathrm{~dB}$ reduction in pond $\mathrm{VV} / \mathrm{HH}$, over the range $25^{\circ} \geq \theta \geq 55^{\circ}$, when comparing the roughest to smoothest conditions. This is a considerable loss of energy, particularly at higher $\theta$, though it is important to recognise that simulations are for a discrete pond.

Bare ice VV/HH observations in Fig. 8 are compared to IEM theory by using fixed roughness parameters and varying $\varepsilon_{\mathrm{r}}$ values representing cold/dry and warm/wet ice conditions (based on modelled $\varepsilon_{\mathrm{r}}$ in Sect. 3.4). Parameters $s_{\mathrm{W}}$ of $2 \mathrm{~mm}, l_{\mathrm{w}}$ of $16 \mathrm{~mm}$ and a power-law ACF with $n=1.1$ were used based on in situ data from Sect. 4.2. The IEM overestimates bare ice $\mathrm{VV} / \mathrm{HH}$, which is likely due to the lack of volume scattering represented by the model. Volume scattering of C-band energy from air inclusions within the desalinated upper layers of level FYI has been observed in freezing and melting conditions during ponding (Scharien et al., 2010) and should be taken into account. However, the

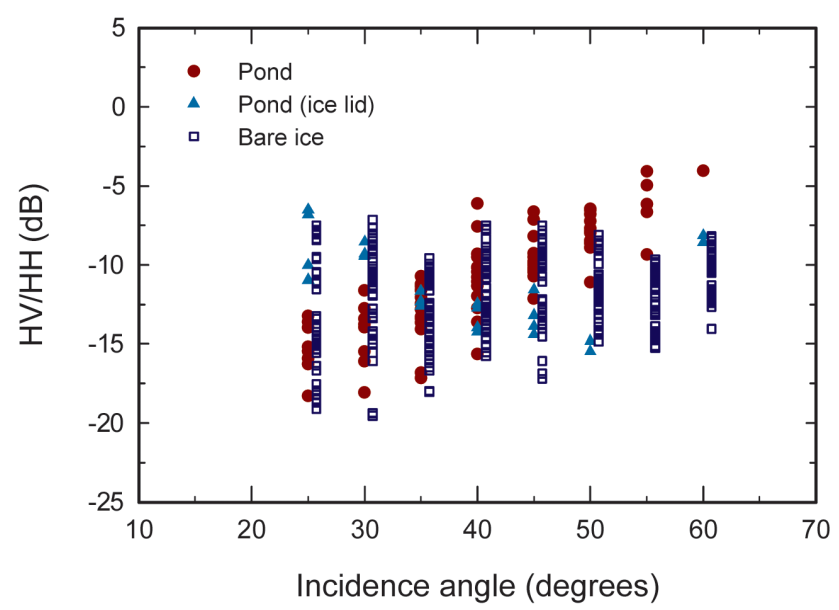

Figure 9. Scatterometer measured polarisation ratio $\mathrm{HV} / \mathrm{HH}$ versus incidence angle, from surface types pond, pond (ice lid) and bare ice. Pond samples were taken from Database B. Bare ice observations are offset along the $x$ axis by $1^{\circ}$ for clarity.

inclusion of a volume-scattering component which accounts for variations in melt water and air bubble inclusion shapes and sizes, changing densities and distributions both vertically and horizontally, without adequate in situ data, would be difficult (Dierking et al., 1999). Instead we note that observed bare ice $\mathrm{VV} / \mathrm{HH}$ tends to null at all $\theta$.

$\mathrm{VV} / \mathrm{HH}$ measured from ponds covered by ice lids are also shown in Fig. 8. There is overlap with bare ice, which suggests the limited utility of $\mathrm{VV} / \mathrm{HH}$ for discriminating ponds from bare ice when ice lids form. When considered in a time series context we suppose that reductions in $\mathrm{VV} / \mathrm{HH}$ to bare ice values, provided a priori identification of ponding, marks the occurrence of ice lids and a negative surface energy balance. This is valuable from a climatological perspective, particularly in marginal ice zones where freeze-melt cycles are more prevalent (IGOS, 2007).

A model was fit to pond observations over the $25^{\circ} \leq$ $\theta \leq 55^{\circ}$ interval in Fig. 8. The curve takes the form of a quadratic:

$\mathrm{VV} / \mathrm{HH}=3.9528+-0.2517 \theta+0.0062 \theta^{2}$,

with a regression $r^{2}=0.74$ and a standard error of $1.3 \mathrm{~dB}$. Equation (8) is similar to models describing the C-band $\mathrm{VV} / \mathrm{HH}$ from a fully developed sea, which are typically derived from empirical fits to homogeneous samples obtained at a larger spatial scale, e.g. from SAR (Vachon and Wolfe, 2011; Zhang et al., 2011).

To further investigate the impact of $l_{\mathrm{w}}$ on IEM simulations of pond $\mathrm{VV} / \mathrm{HH}$, we calculated the difference in simulated $\mathrm{VV} / \mathrm{HH}$ between the smooth $s_{\mathrm{W}}$ of $1 \mathrm{~mm}$ and rough $s_{\mathrm{W}}$ of $7 \mathrm{~mm}$ at $l_{\mathrm{w}}$ increments over a 10 to $100 \mathrm{~mm}$ range (Fig. 9). The power-law ACF with $n=1.41$ was used as mentioned above. The most pronounced effect of $l_{\mathrm{w}}$ with changing $s_{\mathrm{w}}$ occurs at high $l_{\mathrm{w}}$. For example, a change from smooth to 
Table 3. Crosswind to upwind ratios, $\Delta \mathrm{VV} / \mathrm{HH}$ and $\Delta \mathrm{HV} / \mathrm{HH}$ (in $\mathrm{dB}$ ), for three cases at incidence angles $(\theta)$ spanning the 35 to $50^{\circ}$ range at $5^{\circ}$ intervals. Coincident wind speed $U_{10}$, surface rms height $s_{\mathrm{W}}$ and $k s$ values for each case are given.

\begin{tabular}{lrrrrrrrrrrrr}
\hline Case & $U_{10}$ & $s_{\mathrm{W}}$ & $k s$ & \multicolumn{2}{c}{$\theta=35^{\circ}$} & \multicolumn{2}{c}{$\theta=40^{\circ}$} & \multicolumn{2}{c}{$\theta=45^{\circ}$} & \multicolumn{2}{c}{$\theta=50^{\circ}$} \\
\hline & $\mathrm{m} \mathrm{s}^{-1}$ & $\mathrm{~mm}$ & & $\Delta_{\mathrm{HH}}^{\mathrm{VV}}$ & $\Delta_{\mathrm{HH}}^{\mathrm{HV}}$ & $\Delta_{\mathrm{HH}}^{\mathrm{VV}}$ & $\Delta_{\mathrm{HH}}^{\mathrm{HV}}$ & $\Delta_{\mathrm{HH}}^{\mathrm{VV}}$ & $\Delta_{\mathrm{HH}}^{\mathrm{HV}}$ & $\Delta_{\mathrm{HH}}^{\mathrm{VV}}$ & $\Delta_{\mathrm{HH}}^{\mathrm{HV}}$ \\
\hline $\mathrm{A}$ & 7.7 & 3.2 & 0.36 & 2.98 & 5.55 & -0.81 & 6.38 & -0.31 & 6.62 & 0.23 & 8.09 \\
$\mathrm{~B}$ & 4.9 & 1.3 & 0.14 & 0.43 & 5.63 & -0.20 & 7.62 & 0.19 & 6.63 & 0.77 & 7.22 \\
$\mathrm{C}$ & 6.4 & 4.4 & 0.49 & 3.23 & 8.89 & 2.92 & 9.88 & 2.64 & 8.26 & 4.15 & 8.48 \\
\hline
\end{tabular}

rough $s_{\mathrm{w}}$ results in a loss in $\mathrm{VV} / \mathrm{HH}$ of $3 \mathrm{~dB}$ at $40^{\circ} \theta$ when $l_{\mathrm{w}} \geq 60 \mathrm{~mm}$. However, it is the lower 10 to $30 \mathrm{~mm}$ range where the specification of $l_{\mathrm{w}}$ has the greatest impact on the IEM. The effect of $l_{\mathrm{w}}$ saturates at $\geq 60 \mathrm{~mm}$.

Figure 10 shows the HV/HH from ponds (Database B), ponds covered by ice lids, and bare ice across the interval $25^{\circ} \leq \theta \leq 60^{\circ}$. Despite a large amount of scatter in the data, we can make some generalisations in the context of possible feature detection from a mixed resolution cell detected by a spaceborne SAR. The freezing of ponds and formation of ice lids results in increased $\mathrm{HV} / \mathrm{HH}$ relative to free-water ponds at $\theta \leq 30^{\circ}$, whereas a relative decrease is observed at $\theta \geq 45^{\circ}$. Separation between free-water pond and bare ice $\mathrm{HV} / \mathrm{HH}$ is enhanced at $\theta \geq 50^{\circ}$, suggesting the discrimination of ponded from non-ponded zones. However, the aforementioned likelihood of noise contamination must be considered outside of the very low NESZ Cscat system used to obtain these measurements.

\section{Discussion}

\subsection{Potential application to SAR}

The results of this study build on previous work indicating a C-band $\mathrm{VV} / \mathrm{HH}$ approach is suited to pond discrimination based on its sensitivity to high $\varepsilon_{\mathrm{r}}$ free-water compared to bare ice, combined with low sensitivity to the pond $s_{\mathrm{W}}$ according to the Bragg theory. A comprehensive small-scale surface roughness characterisation and the use of microwavescattering theory, in concert with in situ Cscat measurements, have enhanced our understanding of the limitations of a $\mathrm{VV} / \mathrm{HH}$ approach, and provided new insights into the complementary nature of other dual-polarisation parameters such as $\mathrm{HV} / \mathrm{HH}$. The latter is necessary since spaceborne C-band dual-polarisation $\mathrm{HV}+\mathrm{HH}$ data is more commonly available in wide swath $(\geq 400 \mathrm{~km})$ format, e.g. currently from Radarsat-2 and Sentinel 1A, compared to VV $+\mathrm{HH}$ which is limited to narrow swaths, e.g. from current wide quadpolarimetric Radarsat-2 $(50 \mathrm{~km})$ and past alternating polarisation Envisat-ASAR ( $\leq 105 \mathrm{~km})$.

The influence of snow and rough basal ice patches on level FYI, here no longer present during ponding due to a storm event, should be further considered in the context of

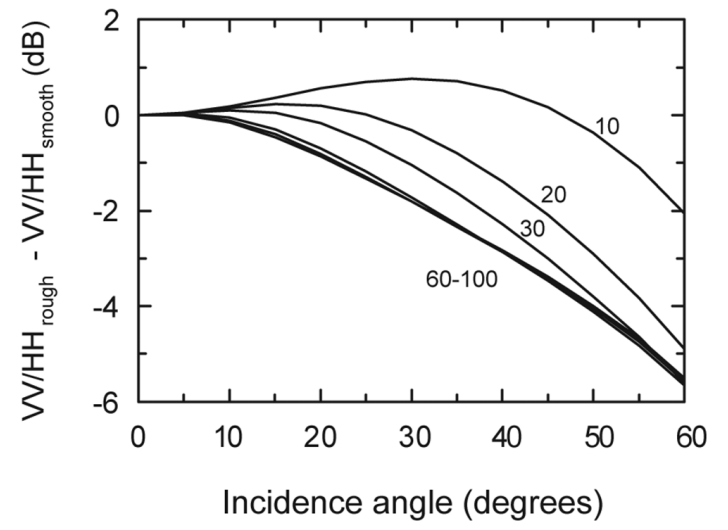

Figure 10. Role of varying $l_{\mathrm{W}}$ on the difference between IEMmodelled $\mathrm{VV} / \mathrm{HH}$ from rough $\left(s_{\mathrm{W}}=7 \mathrm{~mm}\right)$ and smooth $\left(s_{\mathrm{W}}=\right.$ $1 \mathrm{~mm}$ ) ponds. Values in the plot refer to $l_{\mathrm{W}}$ in $\mathrm{mm}$ used in each simulation.

an amorphous seasonal evolution from melt onset to ponding. Melting snow may have higher moisture content than bare ice which, according to the Bragg and IEM theory, increases $\mathrm{VV} / \mathrm{HH}$ by (1) masking volume scattering from air voids in desalinated ice and (2) enhancing the $\varepsilon_{\mathrm{r}}$ contribution to $\mathrm{VV} / \mathrm{HH}$. Rough basal ice patches formed from the re-freezing of melting snow at the snow-ice interface, as also documented in Drinkwater (1989), would decrease VV/HH but enhance single-polarisation backscatter due to higher $s_{\mathrm{i}}$ compared to bare ice.

With regard to ponds on level FYI, the roughness influence on $\mathrm{VV} / \mathrm{HH}$ is critical as demonstrated by $s_{\mathrm{w}}$ measurements and IEM simulations. We were able to assess the $s_{\mathrm{W}}$ effect on $\mathrm{VV} / \mathrm{HH}$ using in situ roughness data, which according to the Bragg theory shows a $\mathrm{VV} / \mathrm{HH}$ dependence on $s_{\mathrm{W}}$ emerging at $U_{10}$ of $6.4 \mathrm{~m} \mathrm{~s}^{-1}$ or greater, depending on pond orientation. However, it is important to recognise limitations in results derived from Cscat measurements. Significant correlations were found between $U_{10}\left(>3 \mathrm{~m} \mathrm{~s}^{-1}\right)$ and both pond $\mathrm{VV} / \mathrm{HH}$ and $\mathrm{HV} / \mathrm{HH}$ using Database A. These measurements were made with the radar antenna directed perpendicular to wave fronts $\left(\phi=0^{\circ}\right)$, introducing the effects of bound, titled waves on $\mathrm{VV} / \mathrm{HH}$ and $\mathrm{HV} / \mathrm{HH}$. Database B measurements were made at $\phi \neq 0^{\circ}$ orientation, a more likely scenario in terms 
of SAR imaging. Nonetheless there are too few samples in Database B for meaningful testing.

The crosswind to upwind experiment, from Table 3, provides the clearest indication of the emergence of a VV/HH dependence on $s_{\mathrm{W}}$ consistent with the Bragg theory. By showing a strong $\mathrm{VV} / \mathrm{HH}$ response to wind-wave orientation beginning with $\sim k s>0.3$, those observations point to pond roughness as a potential error source in SAR-based retrievals. The Cscat measurements in Table 3 are remarkably consistent with the $s_{\mathrm{W}}$ measurements in Fig. 4, as both show the emergence of a $\mathrm{VV} / \mathrm{HH}$ dependence on $s_{\mathrm{w}}$ at $U_{10}$ of $6.4 \mathrm{~m} \mathrm{~s}^{-1}$.

Revisiting our working physical model, pond depth is included as affecting backscatter from ponds on the basis of a previous in situ scatterometer study (Scharien et al., 2012). It is worth reiterating that those results suggested the influence of bottom friction at small pond depths, not the growth of wind-wave amplitudes with increasing depth. No conclusive evidence of a pond depth influence on single and dualpolarisation parameters was observed in this study. Using the deep-water assumption and linear wave theory it is reasonable that, with the shallowest pond excepted, wind-wave growth is independent of pond depth and instead dependent on wind stress, fetch and time. This would suggest that windwave roughness on level FYI ponds is larger than it is on rougher ice types, since ponds on rougher ice are fetch limited due to the influence of topography (Eicken et al., 2004).

Approaches pertaining to rougher FYI or MYI remain to be established. Macro-scale features, such as tilted floes and ridges, introduce multiple scattering, neither studied here nor accounted for by the single-scattering IEM. Modelling must account for a two-scale approach and the superposition of small-scale roughness on large-scale features (Fung, 1994). Conversely, the use of SAR images for VV/HH-based pond information retrievals on the basis of this study would require filtering deformed FYI or MYI ice regions. Lower frequency radar compared to C-band increases the magnitude of roughness falling within the Bragg region. For example, our maximum measured pond $s_{\mathrm{w}}$ of $6.6 \mathrm{~mm}$ yields $k s$ values of 0.18 and 0.06 at L- and P-bands, respectively. Missions such as PALSAR-2 (Phased Array type L-band Synthetic Aperture Radar ) (L-band) and the future BIOMASS (P-band) SAR may hold utility for $\mathrm{VV} / \mathrm{HH}$ retrievals, though more work is required for furtherance of better understand multi-scale and volume-scattering effects.

\subsection{Sources of error}

Integrating microwave-scattering theory with in situ scale observations is essential for understanding complex electromagnetic interactions. This study used the IEM to simulate $\mathrm{VV} / \mathrm{HH}$ from bare ice, showing a systematic overestimation and highlighting the need for including a secondary term to account for volume scattering. IEM estimations of pond $\mathrm{VV} / \mathrm{HH}$ highlighted the upturn in pond $\mathrm{VV} / \mathrm{HH}$ compared to bare ice at $\theta>35^{\circ}$, and sensitivity to $s_{\mathrm{w}}$. Global estimates of roughness parameters were used for simulations, under the assumption that roughness within the Cscat footprint is stationary. However, studies characterising surface roughness for model-based retrievals of soil moisture and identification of changing sea ice conditions have shown that roughness is non-stationary. Parameters $s$ and $l$ have demonstrated a dependence on profile length, as well as correlation with each other, in a manner described by fractional Brownian motion (fBm) (Church, 1988; Manninen, 1997; Baghdadi et al., 2000; Davidson et al., 2000). In spite of this, a recent study has shown that roughness parameters derived from lidar data saturate at a scale that is well below the typical length scale of melting white ice and pond patches, and no longer depend on the measurement process (Landy et al., 2014). Therefore, our approach is appropriate for single-scattering IEM simulations of $\mathrm{VV} / \mathrm{HH}$ from small patches, but extension of the IEM to satellite SAR requires consideration of the effect of measurement length.

Measurements of ice surface roughness obtained from a terrestrial lidar system have several advantages over measurements obtained using traditional techniques, including laser profiling, mesh board or pin profiling. For instance, the two-dimensional lidar measurements are considerably more precise than standard one-dimensional profile measurements. Furthermore, the correlation function of millimetre-centimetre-scale sea ice surface roughness is well characterised by the small sampling interval and large sampling area of the lidar data (Landy et al., 2014). However, the laser scanning technique is potentially limited by several factors. These include (1) the ranging precision of the laser, which depends on the range and reflectivity of the target; (2) the beam divergence of the laser, which can lead to correlation of adjacent samples at sufficient range; and (3) the high-inclination scanning angle of the terrestrial lidar system from nadir. A low scanning range $(<10 \mathrm{~m})$ and relatively high scanner mounting height (2.5 to $3 \mathrm{~m}$ ) were utilised in this study to reduce their impact. However, these factors impose practical limitations on the precision and spatial resolution of lidar samples which are close to the 2 to $5 \mathrm{~mm}$ scale surface roughness of interest here. For a detailed discussion of the suitability of terrestrial lidar for measuring sea ice surface roughness at this scale, see Landy et al. (2014).

The ultrasonic distance sensor technique used to derive pond wave amplitude profiles is less established than other non-invasive methods such as using a scanning laser slope gauge (e.g. Bock and Hara, 1995; Plant et al., 1999). However, logistical constraints imposed by a melting sea ice environment means that instrumentation, such as a scanning laser slope gauge, which illuminates the water surface from below, e.g. in a laboratory wind-wave tank, are impractical. We used previous measurements of FYI melt pond wavelengths (Scharien and Yackel, 2005) and determined that, for our analysis, ultrasonic profile data taken with coincident $U_{10}>4 \mathrm{~m} \mathrm{~s}^{-1}$ (1) have dominant pond wavelengths that 
are several times greater than the transducer spot size; and (2) allow for detection of wind amplitude variations over the range commensurate with our research objectives. From (1) there is a reduced possibility of noise caused by surface geometry such as multiple wind waves within a single sensor footprint. Figure 11 shows the average wave height spectrum derived from the 43 periodograms used in this study, which corresponds to a $\overline{U_{10}}=6.4 \mathrm{~m} \mathrm{~s}^{-1}$. The peak frequency of $3.6 \mathrm{~Hz}$ is captured despite being close to the Nyquist frequency. Using linear wave theory, this yields a dominant wavelength of $12 \mathrm{~cm}$, which is comparable to the $\sim 14 \mathrm{~cm}$ measured in a wind-wave tank at a friction velocity of 0.23 or $U_{10} \sim 6.3 \mathrm{~m} \mathrm{~s}^{-1}$ by conversion through the von Kármán constant (Plant et al., 1999, Fig. 7a). Overall, the agreement between dominant wavelengths, as well as pond $s_{\mathrm{w}}$ derived using different techniques (Fig. 4a), is very encouraging.

\section{Conclusions}

We have presented results from the in situ component of a study conducted in the CAA during June 2012, aimed at understanding the multi-scale, polarimetric, C-band backscatter behaviour of level FYI ice during ponding. Surface roughness and dual-polarisation backscatter measurements were collected from elemental cover type ponds and bare ice. Emphasis was placed on the VV/HH ratio, with the aim of utilising C-band dual-polarisation SAR for pond information retrievals such as the timing of pond formation and drainage, and the measurement of $f_{\mathrm{p}}$. The following research questions were addressed: (1) what are the radar-scale surface roughness characteristics of ponds and ice on level FYI? (2) What is the appropriate scattering model for simulations of pondcovered level FYI? (3) What are the limiting radar and target parameters on the unambiguous retrieval of pond information from dual-polarisation C-band SAR?

For (1) a description of surface roughness parameters relevant to microwave-scattering models was successfully made, using an analysis of lidar measured elevation models and ultrasonic transducer derived melt pond wind-wave amplitude profiles. On level FYI the magnitude of $s$ from strongly wind roughened ponds is greater than it is from bare ice. For (2) we found a $U_{10}$ threshold range of $6.4-8.0 \mathrm{~m} \mathrm{~s}^{-1}$ is used to describe the point at which the limit for the Bragg region is exceeded by pond roughness. A $U_{10}$ range is specified to allow factors related to morphology and its role in wind-wave energy dissipation to be considered. Morphological factors include the relative orientation of wind direction and the principal long axis of ponds, which acts to increase the available fetch, and the interconnectedness of ponds. Bare ice during ponding falls within the Bragg region at C-band and lower frequencies. All roughness data fall within the region of validity of the IEM, which predicts a VV/HH dependence on roughness at all $s_{\mathrm{w}}$. For (3), the primary limiting radar parameter is $\theta$, as angles greater than about $35^{\circ}$ are required

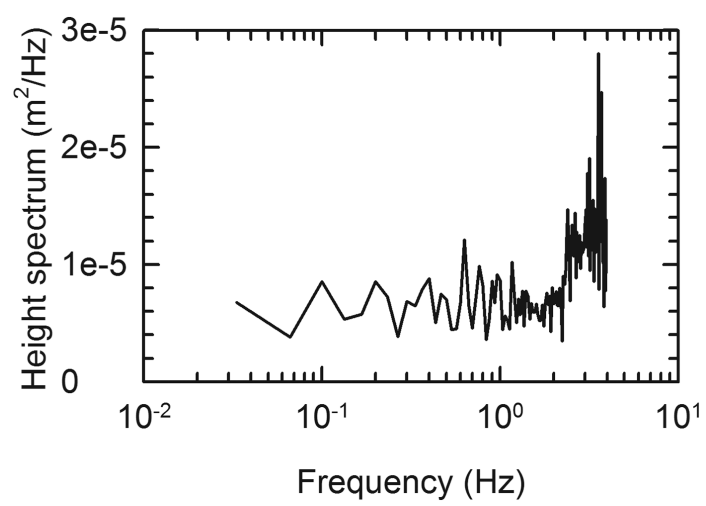

Figure 11. Wave height spectrum of a first-year ice melt pond.

in order to exploit the $\varepsilon_{\mathrm{r}}$ induced contrast in $\mathrm{VV} / \mathrm{HH}$ between free water and ice. The orientation of the radar relative to wind waves is a limiting radar parameter on $\mathrm{VV} / \mathrm{HH}$ when roughness is beyond the Bragg region. Overall, our results suggest the limited utility of $\mathrm{HV} / \mathrm{HH}$ for retrievals of pond information under melting, i.e. free-water, conditions due to the potential for noise floor contamination of HV intensity returns, combined with strong sensitivity (several dB) of $\mathrm{HV} / \mathrm{HH}$ to the orientation of the radar antenna relative to wind waves. Results showing strong $\mathrm{HV} / \mathrm{HH}$ at small $\theta$ $\left(<30^{\circ}\right)$ associated with the presence of ice lids on ponds may prove useful for identifying freeze-thaw events.

This study demonstrates the potential of SAR for monitoring sea ice information pertaining to ponding. Data were evaluated at the in situ scale, which is of much higher spatial and temporal resolution compared to the outlined observation problem from a SAR perspective. Future work will continue to evaluate the potential and limitations of SAR for identifying ponding features within a multi-sensor framework, including those operating in constellation mode. ESA's Sentinel-1 mission (2014 onwards) and Canada's Radarsat Constellation Mission (2018 onwards) will ensure continuity in C-band SAR, though the former will not provide the dual co-polarisation channels needed for VV/HH-based retrievals. Part 2 of this study extends the in situ analysis provided here to the satellite SAR scale, using Radarsat-2 quad-polarisation image data. As with Part 1 , emphasis in Part 2 is placed on VV/HH-based $f_{\mathrm{p}}$ retrievals; in light of their potential for improving level FYI ponding information, all channels within single- and dual-polarisation modes are considered.

Acknowledgements. This paper is dedicated to our colleague Dr. Klaus Hochheim, who lost his life in Sept, 2013, while conducting sea ice research in the Canadian Arctic. Funding for this research was in part provided by Natural Sciences and Engineering Research Council of Canada (NSERC), the Canada Research Chairs and Canada Excellence Research Chairs programs. Randall Scharien is the recipient of a European Space Agency Changing Earth Science 
Network postdoctoral fellowship for the period 2013-2014. Special thanks to John Yackel and his students Chris Fuller, J V Gill, and Carina Butterworth at the University of Calgary, for use of their polarimetric scatterometer. We acknowledge C.J. Mundy and all participants of Arctic-ICE 2012 for providing assistance and support in the field. Special thanks to the Polar Continental Shelf Project (PCSP) for logistical support during the field campaign.

Edited by: D. Feltham

\section{References}

Andreas, E. L., Persson, P. O. G., Jordan, R. E., Horst, T. W., Guest, P. S., Grachev, A. A., and Fairall, C. W.: Parameterizing the turbulent surface fluxes over summer sea ice, 8th Conf. on Polar Meteor. And Oceanog., 9-13 January, San Diego, CA, 2005.

Baghdadi, N., Paillou, P., Grandjean, G., Dubois, P., and Davidson, M.: Relationship between profile length and roughness variables for natural surfaces, Int. J. Remote Sens., 21, 3375-3381, doi:10.1080/014311600750019994, 2000.

Baghdadi, N., Gherboudj, I., Zribi, M., Sahebi, M., Bonn, F., and King, C.: Semi-empirical calibration of the IEM backscattering model using radar images and moisture and roughness field measurements, Int. J. Remote Sens., 25, 593-3623, doi:10.1080/01431160310001654392, 2004.

Barber, D. G., Papakyriakou, T. N., LeDrew, E. F., and Shokr, M. E.: An examination of the relation between the spring period evolution of the scattering coefficient $\left(\sigma^{\circ}\right)$ and radiative fluxes over landfast sea-ice, Int. J. Remote Sensing, 16, 3343-3363, doi:10.1080/01431169508954634, 1995.

Barber, D. G. and Yackel, J. J.: The physical, radiative and microwave scattering characteristics of melt ponds on Arctic landfast sea ice , Int. J. Remote Sens., 20, 2069-2090, doi:10.1080/014311699212353, 1999.

Belchansky, G. I., Douglas, D. C., Eremeev, V. A., and Platonov, N. G.: Variations in the Arctic's multiyear sea ice cover: A neural network analysis of SMMR-SSM/I data, 1979-2004, Geophys. Res. Lett., 32, L09605, doi:10.1029/2005GL022395, 2005.

Bock, E. J. and Tetsu H.: Optical Measurements of CapillaryGravity Wave Spectra Using a Scanning Laser Slope Gauge, J. Atmos. Oceanic Technol., 12, 395-403, doi:10.1175/15200426(1995)012<0395:OMOCGW>2.0.CO;2, 1995.

Brekke, C., Holt, B., Jones, C., and Skrunes, S.: Towards oil slick monitoring in the Arctic environment, Proc. POLinSAR 2013, Frascati, Italy, 8 pp., 28 January-1 February, 2013.

Church, E. L.: Fractal surface finish, Appl. Opt., 278, 1518-1526, 1988.

Davidson, M. W. J., Le Toan, T., Mattia, F., Satalino, G., Manninen, T., and Borgeaud, M.: On the characterization of agricultural soil roughness for radar remote sensing studies, IEEE Trans. Geosci. Remote Sens., 38, 630-640, doi:10.1109/36.841993, 2000.

De Abreu, R., Yackel, J. J., Barber, D. G., and Arkett, M.: Operational satellite sensing of Arctic first-year sea ice melt, Can. J. Remote Sens., 27, 487-501, 2001.

Donelan, M. A. and Pierson Jr., W. J.: Radar scattering and equilibrium ranges in wind-generated waves with application to scatterometry, J. Geophys. Res., 92, 4971-5029, doi:10.1029/JC092iC05p04971, 1987.
Drinkwater, M. R. and Crocker, G. B.:, Modeling changes in the dielectric and scattering properties of young snow covered sea ice at GHz frequencies, J. Glaciol., 34, 274-282, 1988.

Drinkwater, M. R.: LIMEX '87 Ice Surface Characteristics: Implications for C-Band SAR Backscatter Signatures, IEEE T. Geosci. Remote, 27, 501-513, doi:10.1109/TGRS.1989.35933, 1989.

Dierking, W., Pettersson, M. I., and Askne, J.: Multifrequency scatterometer measurements of Baltic Sea ice during EMAC-95, Int. J. Remote Sens., 20, 349-372, doi:10.1080/014311699213488, 1999.

Eicken, H., Krouse, H. R., Kadko, D., and Perovich, D. K.: Tracer studies of pathways and rates of meltwater transport through Arctic summer sea ice, J. Geophys. Res., 107, SHE 22-1-SHE 22-20, doi:10.1029/2000JC000583, 2002.

Eicken, H., Grenfell, T. C., Perovich, D. K., Richter-Menge, J. A., and Frey, K.: Hydraulic controls on summer Arctic pack ice albedo, J. Geophys. Res., 109, C08007, doi:10.1029/2003JC001989, 2004.

ESA: Sentinel-1: ESA's radar observatory mission for GMES operational services, ESA SP-1322/1, 2012.

Fung, A. K.: Microwave Scattering and Emission Models and Their Applications, Artech House, Inc., Norwood, Ma, 1994.

Geldsetzer, T. and Yackel, J. J.: Sea ice type and open water discrimination using dual co-polarized C-band SAR, Can. J. Remote Sens., 35, 73-84, doi:10.5589/m08-075, 2009.

Geldsetzer, T., Mead, J. B., Yackel, J. J., Scharien, R. K., and Howell, S. E. L.: Surface-based polarimetric C-band scatterometer for field measurements of sea ice, IEEE Trans. Geosci. Remote Sens., 45, 3405-3416, doi:10.1109/TGRS.2007.907043, 2007.

Hallikainen, M. T. and Winebrenner, D. P.: The physical basis for sea ice remote sensing, in: Microwave Remote Sensing of Sea Ice, Geophysical Monograph 68, edited by: Carsey, F., 29-46, AGU, Washington, D.C, 1992.

Hajnsek, I., Pottier, E., and Cloude, S. R.: Inversion of surface parameters from polarimetric SAR, IEEE Trans. Geosci. Remote Sens., 41, 727-744, doi:10.1109/TGRS.2003.810702, 2003.

Hanesiak, J. M., Yackel, J. J., and Barber, D. G.: Effect of melt ponds on first-year sea ice ablation-integration of RADARSAT1 and thermodynamic modelling, Can. J. Remote Sens., 27, 433-442, 2001a.

Hanesiak, J. M., Barber, D. G., De Abreu, R. A., and Yackel, J. J.: Local and regional albedo observations of arctic first-year sea ice during melt ponding, J. Geophys. Res., 106, 1005-1016, doi:10.1029/1999JC000068, 2001b.

Heygster, G., Alexandrov, V., Dybkjær, G., von HoyningenHuene, W., Girard-Ardhuin, F., Katsev, I. L., Kokhanovsky, A., Lavergne, T., Malinka, A. V., Melsheimer, C., Toudal Pedersen, L., Prikhach, A. S., Saldo, R., Tonboe, R., Wiebe, H., and Zege, E. P.: Remote sensing of sea ice: advances during the DAMOCLES project, The Cryosphere, 6, 1411-1434, doi:10.5194/tc-61411-2012, 2012.

Holland, M. M., Bailey, D. A., Briegleb, B. P., Light, B., and Hunke, E.: Improved sea ice shortwave radiation physics in ccsm4: the impact of melt ponds and aerosols on arctic sea ice, J. Climate, 25, 1413-1430, doi:10.1175/JCLI-D-11-00078.1, 2012.

Howell, S. E. L., Tivy, A., Yackel, J. J., and Scharien, R. K.: Application of a SeaWinds/QuikSCAT sea ice melt algorithm for assessing melt dynamics in the Canadian Arctic Archipelago, J. Geophys. Res., 111, C07025, doi:10.1029/2005JC003193, 2006. 
IGOS: Integrated Global Observing Strategy Cryosphere Theme Report - For the Monitoring of our Environment from Space and from Earth, WMO/TD-No. 1405, World Meteorological Organization, Geneva, 100 pp., 2007.

Kwok, R., Cunningham, G. F., Wensnahan, M., Rigor, I., Zwally, H. J., and Yi, D.: Thinning and volume loss of the Arctic Ocean sea ice cover: 2003-2008, J. Geophys. Res., 114, C07005, doi:10.1029/2009JC005312, 2009.

Landy, J. C., Isleifson, D., Komarov, A. S., and Barber, D. G.: Parameterization of centimetre-scale sea ice surface roughness using terrestrial LiDAR, IEEE T. Geosci. Remote, 53, 1271-1286, doi:10.1109/TGRS.2014.2336833, 2014.

Livingstone, C. E., Singh, K. P., and Gray, L.: Seasonal and regional variations of active/passive microwave signatures of sea ice, Geosci. Remote Sens., IEEE Trans., GE-25, 159-173, doi:10.1109/TGRS.1987.289815, 1987.

Manninen, A. T.: Surface roughness of Baltic sea ice, J. Geophys. Res., 102, 1119-1139, doi:10.1029/96JC02991, 1997.

Markus, T., Cavalieri, D. J., Tschudi, M. A., and Ivanoff, A.: Comparison of aerial video and Landsat 7 data over ponded sea ice, Remote Sens. Environ., 86, 458-469, doi:10.1016/S00344257(03)00124-X, 2003.

Mätzler, C., Aebisher, H., and Schanda, E.: Microwave dielectric properties of surface snow, IEEE J. Ocean. Eng., 9, 366-371, doi:10.1109/JOE.1984.1145644, 1984.

Morassutti, M. P. and Ledrew, E. F.: Albedo and depth of melt ponds on sea ice, Int. J. Climatol., 16, 817-838, doi:10.1002/(SICI)1097-0088(199607)16:7<817::AIDJOC44>3.0.CO;2-5, 1996.

Nakamura, K., Wakabayashi, H., Uto, S., Ushio, S., and Nishio, F.: Observation of sea-ice thickness using ENVISAT data from Lützow-Holm Bay, East Antarctica, IEEE Geosci. Remote Sens. Lett., 6, 277-281, doi:10.1109/LGRS.2008.2011061, 2009.

Nghiem, S. V. and Bertoia, C.: Study of multi-polarization C-band backscatter signatures for Arctic sea ice mapping with future satellite SAR, Can. J. Remote Sens., 27, 387-402, 2001.

Perovich, D. K., Grenfell, T. C., Richter-Menge, J. A., Light, B., Tucker III, W. B., and Eicken, H.: Thin and thinner: Sea ice mass balance measurements during SHEBA, J. Geophys. Res., 108, 8050, doi:10.1029/2001JC001079, 2003.

Perovich, D. K., Light, B., Eicken, H., Jones, K. F., Runciman, K., and Nghiem, S. V.: Increasing solar heating of the Arctic Ocean and adjacent seas, 1979-2005: Attribution and role in the ice-albedo feedback, Geophys. Res. Lett., 34, L19505, doi:10.1029/2007GL031480, 2007.

Plant, W. J., Keller, W. C., Hesany, V., Hara, T., Bock, E., and Donelan, M. A.: Bound waves and Bragg scattering in a wind-wave tank, J. Geophys. Res., 104, 3243-3263, doi:10.1029/1998JC900061, 1999.

Polashenski, C., Perovich, D., and Courville, Z.: The mechanisms of sea ice melt pond formation and evolution, J. Geophys. Res., 117, C01001, doi:10.1029/2011JC007231, 2012.

Rösel, A. and Kaleschke, L.: Exceptional melt pond occurrence in the years 2007 and 2011 on the Arctic sea ice revealed from MODIS satellite data, J. Geophys. Res., 117, C05018, doi:10.1029/2011JC007869, 2012.
Rösel, A., Kaleschke, L., and Birnbaum, G.: Melt ponds on Arctic sea ice determined from MODIS satellite data using an artificial neural network, The Cryosphere, 6, 431-446, doi:10.5194/tc-6431-2012, 2012.

Rösel, A. and Kaleschke, L.: Comparison of different retrieval techniques for melt ponds on Arctic sea ice from Landsat and MODIS satellite data, Ann. Glaciol., 52, 185-191, 2011.

Scharien, R. K. and Yackel, J. J.: Analysis of surface roughness and morphology of first-year sea ice melt ponds: Implications for microwave scattering, IEEE Trans. Geosci. Remote Sens., 43, 2927-2939, doi:10.1109/TGRS.2005.857896, 2005.

Scharien, R. K., Yackel, J. J., Granskog, M. A., and Else, B. G. T.: Coincident high resolution optical-SAR image analysis for surface albedo estimation of first-year sea ice during summer melt, Remote Sens. Environ., 111, 160-171, doi:10.1016/j.rse.2006.10.025, 2007.

Scharien, R. K., Geldsetzer, T., Barber, D. G., Yackel, J. J., and Langlois, A.: Physical, dielectric, and $\mathrm{C}$ band microwave scattering properties of first-year sea ice during advanced melt, J. Geophys. Res., 115, C12026, doi:10.1029/2010JC006257, 2010.

Scharien, R. K., Yackel, J. J., Barber, D. G., Asplin, M., Gupta, M., and Isleifson, D.: Geophysical controls on $\mathrm{C}$ band polarimetric backscatter from melt pond covered Arctic first-year sea ice: Assessment using high-resolution scatterometry, J. Geophys. Res., 117, C00G18, doi:10.1029/2011JC007353, 2012.

Scharien, R. K., Hochheim, K., Landy, J., and Barber, D. G.: First-year sea ice melt pond fraction estimation from dualpolarisation C-band SAR - Part 2: Scaling in situ to Radarsat2, The Cryosphere, 8, 2163-2176, doi:10.5194/tc-8-2163-2014, 2014.

Scheuchl, B., Flett, D., Caves, C., and Cumming, I.: Potential of RADARSAT-2 for operational sea ice monitoring, Can. J. Remote Sens., 30, 448-461, 2004.

Thomsen, B. B., Nghiem, S. V., and Kwok, R.: Polarimetric C-band SAR observations of sea ice in the Greenland Sea, Proc. Int. Geoscience and Remote Sensing Symp., Seattle, WA, 2502-2504, doi:10.1109/IGARSS.1998.702259, 1998.

Tschudi, M. A., Maslanik, J. A., and Perovich, D. K.: Derivation of melt pond coverage on Arctic sea ice using MODIS observations, Remote Sens. Environ., 112, 2605-2614, doi:10.1016/j.rse.2007.12.009, 2008

Ulaby, F. T., Moore, R. K., and Fung, A. K.: Microwave Remote Sensing: Active and Passive. From Theory to Applications, Vol. III, Artech House, Inc., Norwood, Massachusetts, 1986.

Untersteiner, N.: Arctic summer time: The short summer of 2004 [Web essay], available at: http://www.arctic.noaa.gov/essay_ untersteiner3.html, 2004

Vachon, P. W. and Wolfe, J.: C-Band cross-polarization wind speed retrieval, Geosci. Remote Sens. Lett., 8, 451-455, doi:10.1109/LGRS.2010.2085417, 2011.

Wu, T. D., Chen, K. S., Shi, J., and Fung, A. K.: A transition model for the reflection coefficient in surface scattering, IEEE Trans. Geosci. Remote Sens., 39, 2040-2049, doi:10.1109/36.951094, 2001. 
Yackel, J. J. and Barber, D. G.: Melt ponds on sea ice in the Canadian Archipelago: 2. On the use of RADARSAT-1 synthetic aperture radar for geophysical inversion, J. Geophys. Res., 105, 22061-22070, doi:10.1029/2000JC900076, 2000.

Yackel, J. J., Barber, D. G., Papakyriakou, T. N., and Breneman, C.: First-year sea ice spring melt transitions in the Canadian Arctic Archipelago from time-series synthetic aperture radar data, 1992-2002, Hydrol. Process., 21, 253-265, doi:10.1002/hyp.6240, 2007.

Zabel, I., Jezek, K., Gogineni, S., and Kanagaratnam, P.: Search for proxy indicators of young sea ice thickness, J. Geophys. Res., 101, 6697-6709, doi:10.1029/95JC02957, 1996.
Zege, E., Katsev, I., Malinka, A., Prikhach, A., and Heygster, G.: New approach for radiative transfer in sea ice and its application for sea ice satellite remote sensing, Radiation Processes in the Atmosphere and Ocean (IRS2012), AIP Conf. Proc. 1531, 43-46, doi:10.1063/1.4804703, 2012.

Zhang, B., Perrie, W., and He, Y.: Wind speed retrieval from RADARSAT-2 quad-polarization images using a new polarization ratio model, J. Geophys. Res., 116, C08008, doi:10.1029/2010JC006522, 2011.

Zribi, M., Baghdadi, N., and Guerin, C.: Analysis of Surface Roughness Heterogeneity and Scattering Behavior for Radar Measurements, Geosci. Remote Sens., IEEE Trans., 44, 2438-2444, doi:10.1109/TGRS.2006.873742, 2006. 